Portland State University

PDXScholar

$1-1-1983$

\title{
Global awareness of administrators in higher education in the State of Oregon
}

\author{
Elizabeth Marsh O'Malley
}

Portland State University

Follow this and additional works at: https://pdxscholar.library.pdx.edu/open_access_etds Let us know how access to this document benefits you.

\section{Recommended Citation}

O'Malley, Elizabeth Marsh, "Global awareness of administrators in higher education in the State of Oregon" (1983). Dissertations and Theses. Paper 829.

https://doi.org/10.15760/etd.829

This Dissertation is brought to you for free and open access. It has been accepted for inclusion in Dissertations and Theses by an authorized administrator of PDXScholar. Please contact us if we can make this document more accessible: pdxscholar@pdx.edu. 


\title{
GLOBAL AWARENESS OF ADMINISTRATORS \\ IN HIGHER EDUCATION IN THE \\ STATE OF OREGON
}

by

ELIZABETH MARSH O'MALLEY

A dissertation submitted in partial fulfillment of the requirements for the degree of

DOCTOR OF EDUCATION

\author{
Portland State University \\ Oregon State University \\ University of Oregon
}

1983 
TO THE OFFICE OF GRADUATE STUDIES AND RESEARCH:

The members of the committee approve the dissertation of Elizabeth M. O'Malley, presented July 5, 1983.
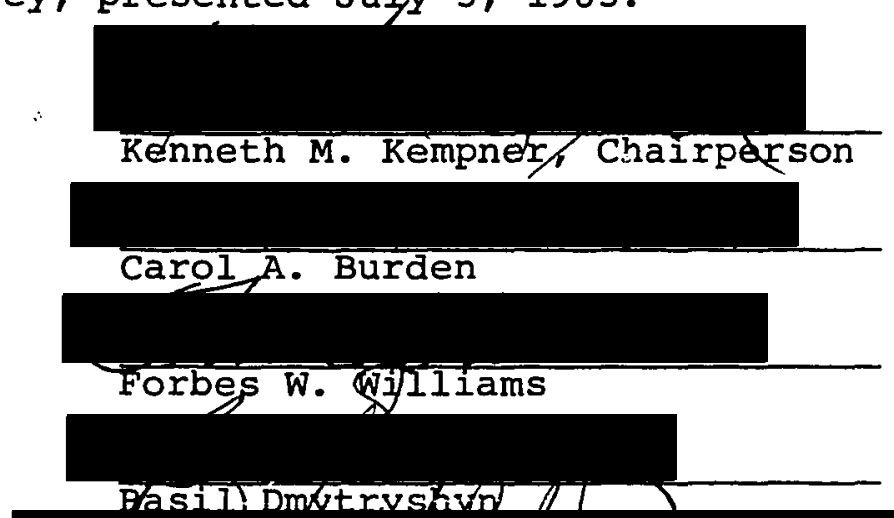

APPRQVED :

$$
\text { Ralph } X \cdot \text { Rands }
$$
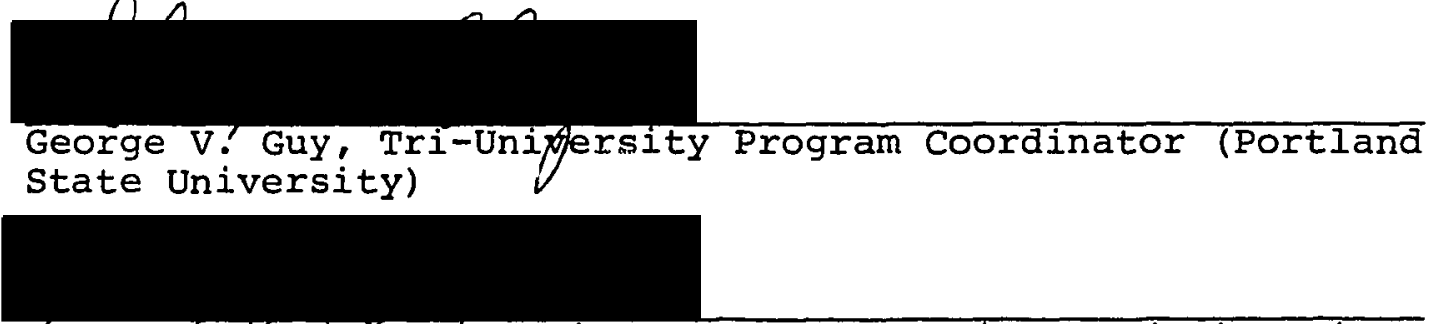

Max Abbott, Tri-University Program Coordinator (University of oregon)

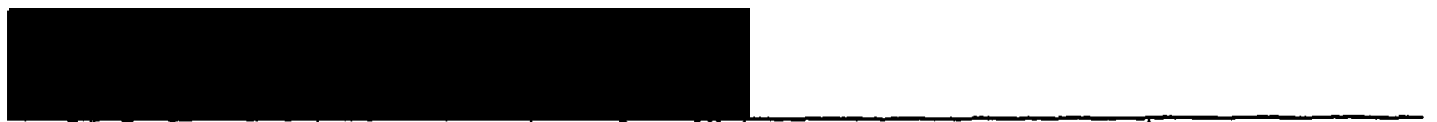

Thomas E. Grigsby, Tri-Univeffsity Program Coordinator (Oregon State University)

Donald J. Ley, Desin, School of Education (Portland state University)

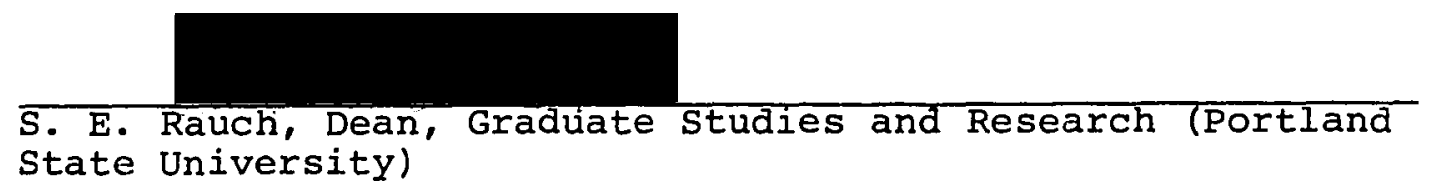


AN ABSTRACT OF THE DISSERTATION OF Elizabeth M. O'Malley for the Doctor of Education presented July 5, 1983.

Title: Global Awareness of Administrators in Higher Education in the state of oregon.

APPROVED BY MEMBERS OF THE DISSERTATION COMMITTEE:

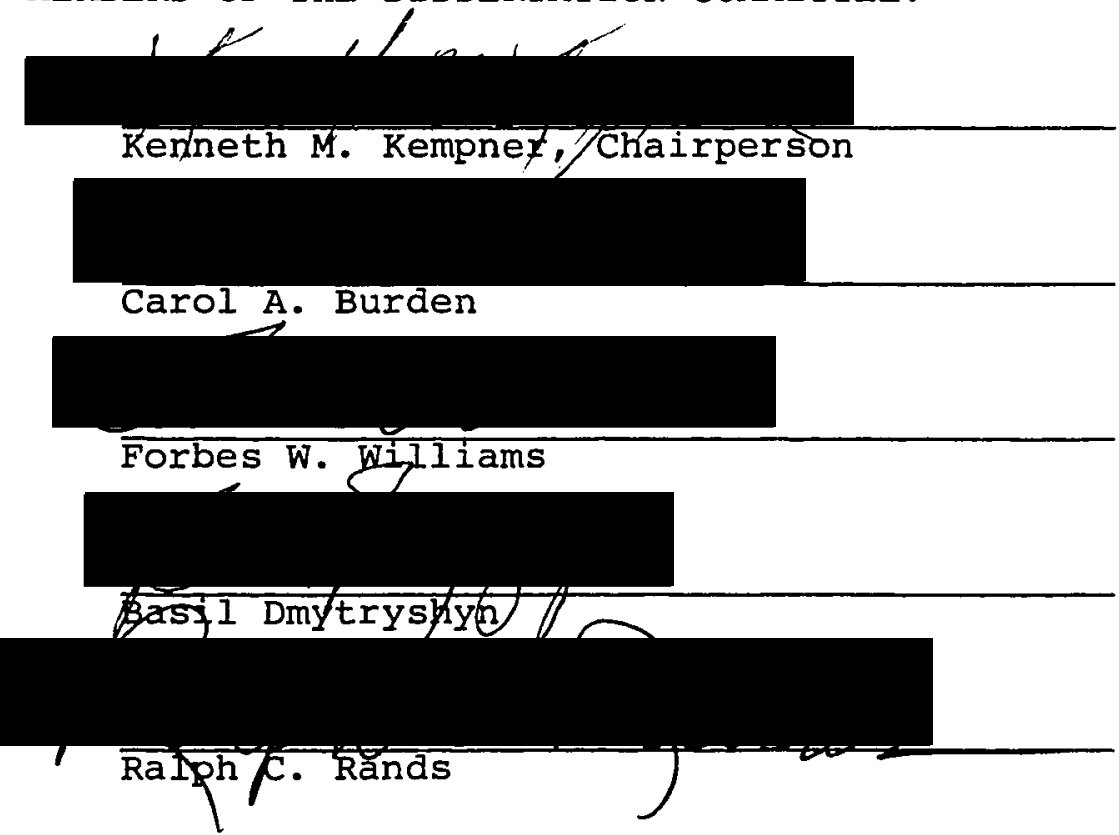

The development of worldmindedness is an educational objective endorsed by many prominent educators. How worldmindedness can be created and developed is a question acknowledged in much of the literature and needs to be answered if the world is to move toward a future of peace and understanding.

Authorities agree that to prepare Americans for an 
interdependent world, the United States must incorporate global education into the nation's existing educational system. This task will require strong leadership on America's college campuses. Consequently, before an effective worldmindedness program can be established in inst. tutions of higher learning, administrators' attitudes toward such a program must be determined. Just as a person's attitude toward nationalism/internationalism can indicate that person's response to government policies, so also are administrators' attitudes firm indicators of their interest in higher education's implementation of worldmindedness programs.

For this investigation, worldmindedness was defined as a value orientation toward the human race rather than knowledge or interest in international relations. Sixty administrators in higher education in the state of cregon were studied to ascertain if their family, personal and educational backgrounds had any effect on their worldminded attitudes. Respondents were employed at community colleges, private or state institutions, with positions in the administrative hierarchy ranging from presidents to directors or deans of academic departments.

Data were obtained utilizing two instruments combined into one: a questionnaire composed of demographic socioeconomic, personal and educational background information, and the "World-mindedness Scale," developed by Donald L. Sampson and Howard P. Smith. 
The results of the study were encouraging. Only 10.38 of the subjects were below the neutral score, $39.7 \%$ were above the mean and 31.08 were in the top third of the Worldmindedness scale indicating strong worldmindedness. A total of 87.98 were above the theoretical neutral.

The findings of the Ijterature were supported by the study. Socio-economic backgrounds, educational experience (formal and informal), college major, course work, foreign language study, travel and type of world news garnering were found to assist in the development of worldminded attitude. No significant differences were found between administrators and institution of employment. 
Dedicated to my children

Anne, Matthew, Katherine and John 


\section{ACKNOWLEDGMENTS}

I wish to express my appreciation for the effort, time and caring that have been provided by my dissertation committee: Dr. Kenneth M. Kempner, Chairman; Dr. Carol A. Burden and Dr. Forbes W. Williams, School of Education, Portland State University; Dr. Basil Dmytryshyn, Department of History, Portland State University, and Dr. Ralph C. Rands, College of Education, University of Oregon. Without their continuing scholarly criticism and interest, this dissertation would not have come to fruition.

Acknowledgment is given to Dr. John Villaume for his assistance with computer programing.

Lastly, I wish to thank my daughter, Katy, Ior not letting me give up. 
TABLE OF CONTENTS

PAGE

DEDICATION • • • • • • • • • • • • • • • •

iii

ACKNOWLEDGMENTS

iv

IIST OF TABLES

vii

CHAPTER

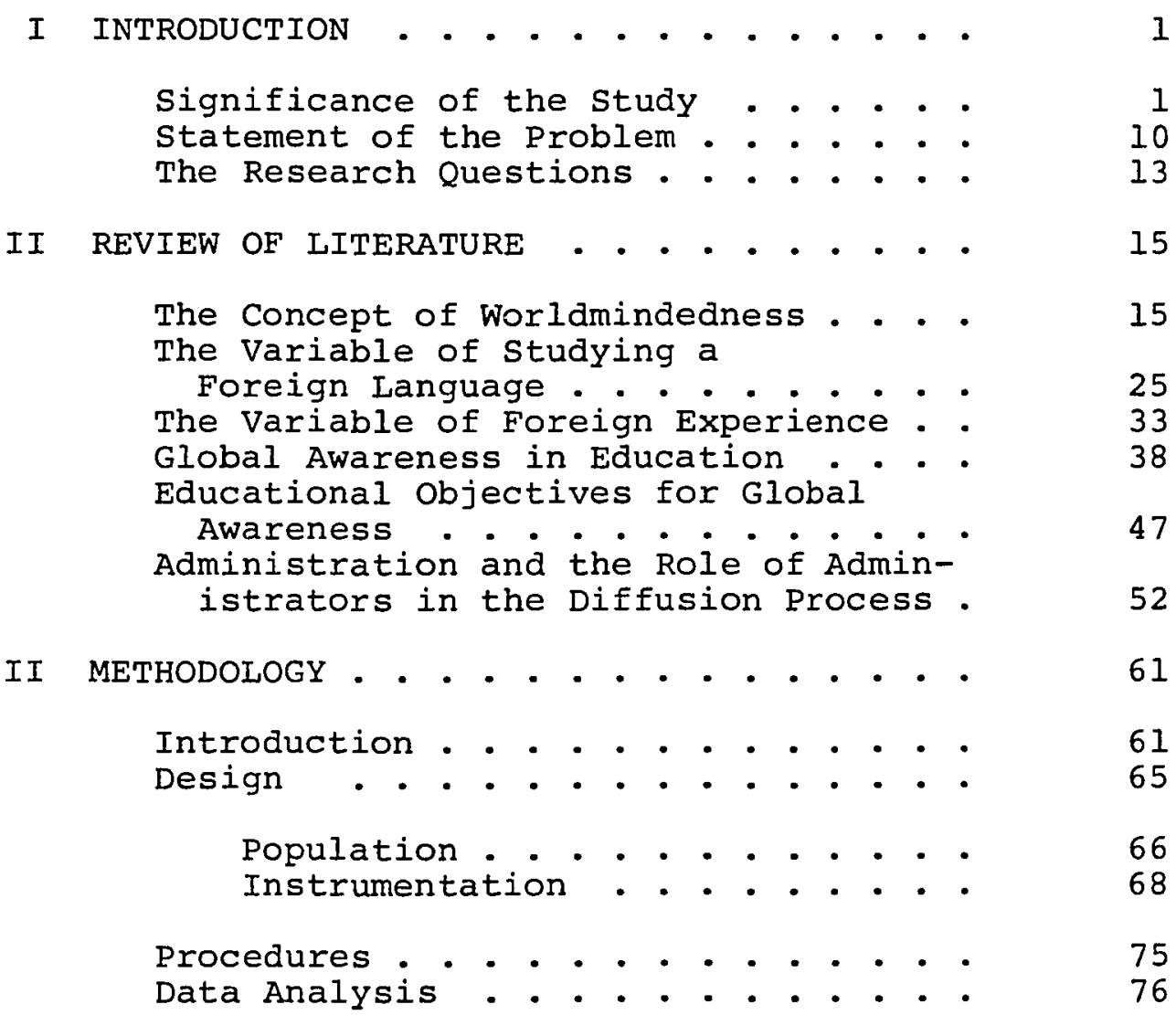


Introduction . . . . . . . . . . .

$V$ SUMMARY, CONCLUSIONS AND RECOMMENDATIONS 103

Worldmindedness Among Oregon Administrators . . . . . . . . . 104 Relevance of Statistical Significance in Educational Research . . . . . 113

Recommendations for Worldmindedness Development .......... . 116

Future Research ....... 120

A SELECTED BIBLIOGRAPHY . . . . . . . . . . . 123

APPENDICES •. . . . . . . . . . . . . . . . 135

APPENDIX A - Table I Through XIII . . . . 135

$\begin{aligned} \text { APPENDIX B - } & \text { Cover Letter and Follow-up } \\ & \text { Correspondence . . . . . . } 149\end{aligned}$

APPENDIX C - Questionnaire . . . . . . 154 
LIST OF TABLES

TABLE

PAGE

I The Worldmindedness scale Format of Proand Anti-Worldmindedness Questions . . . 70

II The Number and Percent of Completed Questionnaires Returned in Response to Each Mailing . . . . . . . . . . . 76

III Administrators' Educational Level . . . . . 82

IV Distribution of Respondents to Major Field for Highest Degree Earned . . . . . . 83

$\mathrm{V}$ Respondents' Foreign Language Study . . • . 83

VI Respondents' Institution of Employment . . . 84

VII Respondents' Worldminded Score Reduced to a Trichatmous Scale... . . . . . 85

VIII Arithmetic Means Ranging From 0 to 6 of the Eight Dimensions of the Worldmindedness Scale ............... . . 86

IX Respondents' Educational Level and Vacation Travel . . . . . . . . . . . 90

$\mathrm{X}$ Respondents' Ages and High and Low Worldmindedness Scores . . . . . . . . . . . 92

XI Respondents' Political Party and High and Low Worldmindedness Scores . . . . . 93 
List of Tables (continued)

TABLE

PAGE

XII Respondents' Worldmindedness Score and Highest Degree Earned . . . . . . . . 97

XIII Respondents' Worldmindedness Scores and Institution of Employment . . . . . . . 99

XIV Respondents' Outside the United States Student and Teaching Experience Duration and Institution of Employment . . . . . 101 
CHAPTER I

INTRODUCTION

SIGNIFICANCE OF THE STUDY

\section{Global Interdependence}

over the past half-century revolutionary changes have occurred in every geographical region of the globe. These fundamental changes have made today's world qualitatively different from yesterday's. The emergence of a global economy, the development of a global electronic communications system, the expansion of a network of cross-national organizations and associations, the spread of atomic power, and the growth of worldwide literacy have all contributed to a new world awareness. Such awareness, however, can be perplexing or even frightening, especially to Americans who have relied on an insular geographical position to shield them from foreign influence. If Americans' perceptions of the outside world were romantic, Americans now know the world to be violent. If the foreign world seemed distant and unimportant, Americans now realize that it affects their daily lives.

George w. Bonham, chairman of the National Task Force on Education and the World View, executive director of the Council on Learning and editor-in-chief of Change, recently 
has stated that mankind now lives in a world that has become increasingly anarchical, unpredictable and not of America's design. The Task Force statement on Education and the World View concurs that the world is in unprecedented flux and uncertainty (Task Force Statement, 1981).

As global interdependence becomes a reality and the world's destiny determined by actions of nations working together, changes in understanding are essential for survival. What is needed is a major change in the way Americans, as a nation, perceive global events and their relations with other nations. This is the opinion of Barbara Burn, executive director of the President's Commission on Foreign Language and International Studies (Burn, 1980). Stephen Rhinesmith, international president and chief executive officer of American Field Service (AFS) International/Intercultural Programs, believes that global problems will be met only when Americans and others can reach beyond their own traditional cultural perspectives and overcome their initial psychological anxieties when meeting the challenges of a global society (Richardson, $1979)$.

The Preamble of the Constitution of UNESCO points out that

ignorance of each other's ways and lives has been a common cause, throughout the history of mankind, of that suspicion and mistrust between peoples of the world through which their differences have all too often broken into war. (Kenworthy, 1952) 
The need for global understanding can be placed in perspective by realizing that the historic division between domestic and global agendas has been disappearing rapidly. The internationalization of national economies and markets has already been advanced (Task Force Statement, 1981). It has been established that in recent years the world has been consuming 30,000 gallons of petroleum each second. The United States has been consuming one-third of that amount, and importing 30 percent of what it consumes (Bray, 1981). Between 1950 and 1979, American exports increased from $\$ 10.2$ billion to $\$ 175.3$ billion (Task Force Statement, 1981). Particularly dramatic has been the growth of multinational corporations whose combined products now exceed the Gross National Products of most countries in the world (Burn, 1980a). One-fourth of each new dollar of direct American investment goes abroad (Bray, 1981). American assets abroad grew from $\$ 19$ billion in 1950 to $\$ 377$ billion in 1979. Foreign direct investments in the United States rose from $\$ 3.4$ billion to $\$ 40.0$ billion during the same period (Task Force statement, 1981). These statistics point clearly to the economic global interdependence of the world's nations.

The speed of change and growth of global interdependence has become an historical trend. John Platt has stated that the current transformation "is as enormous as ten Industrial Revolutions and Protestant Reformations all rolled into one and occurring within a single generation" 
(Cornish, 1977).

The staff director for the White House's National Goals Research staff warned, as early as 1972, that "the change during the next 30 years may be equal in scope to the change of the past two or three centuries" (Cornish, 1977).

In 1965, in his speech at the bicentennial celebration of the birth of the founder of the Smithsonian Institution, President Lyndon B. Johnson said:

We know today that certain truths are selfevident in every nation on this earth: that ideas, not armaments, will shape our lasting prospects of peace: that the conduct of our foreign policy will advance no faster than the curriculum of our classroom, and that knowledge of our citizens is the treasure which grows only when it is shared. (Johnson, 1965)

Ideas, education and the courage to reach out to foreign nations, then, carry the promise of global understanding. Without this promise--nourished by the nation's teachers and schools but challenged by a rapidly changing earth--prospects for world peace and progress may be lost.

\section{Higher Education}

The question confronting American higher education and the American people in the $1980 \mathrm{~s}$ is whether or not to improve global education. In the judgment of many competent experts, including the 1980 report by the Carnegie Council on Policy Studies in Higher Education, the answer is an unequivocal yes, for two principal reasons: First, the concern of higher education should include the whole 
world, not just part of it; and, second, knowledge never has had, nor should it now respect, national boundaries. What has proven to be certain by universal standards should be no less true in China than in the United States. In other words, intellectuals of all nations throughout history have contributed, are contributing and will contribute to the scope of human knowledge and understanding.

It is inconceivable, therefore, that any country that aspires to international leadership can exercise that role if its people are undereducated in, or are ignorant of, global affairs (Burn, 1980b).

To meet that challenge, in 1966 the Congress of the United States passed the International Education Act. Its preamble bluntly declared that

A knowledge of other countries is of the utmost importance in promoting mutual understanding and cooperation between nations, . . to meet the requirements of world leadership. (U.S. Code, I, 1966, P. 1246)

A recent poll by the Potomac Associates, a ronprofit research organization concerned with developing human resources, has shown that Americans who have better and/or higher social status pay more attention to world events and show a higher level of interest in foreign policy and generally are more supportive of international commitments. The study also has shown that poorer and less educated Americans see few connections between global issues and their own lives (Cleveland, 1980).

The 1980 Carnegie Council Study showed that 14-year- 
old American students rate near the top of awareness in local, state and national affairs, but rate "next to last" in knowledge of world affairs, when those students are compared with others in eight countries surveyed (Burn, 1980a).

To meet the challenge of educating Americans about the importance of global awareness, U.S. colleges and universities must provide new directions, especially in curriculum. In 1965, a Task Force for the Association of state Colleges and Universities asserted that the most significant research in global education leads to a better understanding of the formation of U.S. public opinion about foreign affairs (1975).

The conclusion of the Task Force on Education and the World View (1981) states that a fundamental understanding of the key elements of global and national interdependence should constitute a college graduate's understanding, acquired through study in the humanities, social sciences, sciences and other disciplines. The President's Commission on Foreign Language and International Studies, in a 1979 report entitled "Strength Through wisdom: A Critique of U.S. Capability," recommended that all undergraduates have two or three required courses in international or comparative perspectives, and that faculty and students should have opportunities to strengthen or acquire international knowledge and skills.

Barbara Burn, executive director of the President's 
Commission on Foreign Language and International studies, has stated that for international education to be effective, not only should more courses be offered on other countries, but the entire curriculum should be permeated by an international outlook (Burn, 1980b). The Oregon Governor's Commission on Foreign Language and International Studies reached an identical conclusion when in its report in 1982 it recommended that

All educational insticutions, especially at the postsecondary level, emphasize international issues in conducting community education programs, stressing the local and regional impact of those issues. (Final Report, 1982)

In a word, authorities agree that to prepare Americans and American children for an interdependent world, the United States must incorporate global education into the nation's already existing educational system (Burn, 1980a; Lawson, 1969; Martorana \& Shannon, 1979; Task Force Statement, 1981; Tonkin \& Edwards, 1981; Willner, 1982). This task will require strong leadership on America's college campuses.

Clark Kerr, chairman of the Carnegie Council on Policy Studies in Higher Education, has stated that beyond the measures that can be taken on the campuses, the leaders of American colleges and universities have a responsibility and an opportunity to exert leadership to expanding the international dimension of learning at all levels of the nation's educational system (Burn, 1980b). 


\section{Aáministrators}

For global education to become a top priority, insuring cooperation and support at all levels institutionally, administrators must be ready to propose, stimulate, conduct and support global education on each respective campus.

According to a report released in 1980 by the Agency for International Development, to bring about a change in attitude by colleges and universities toward international education, the first essential element must be commitment at key levels of administrative and academic leadership. The Task Force statement is clear in its intent when it states that global perspectives, as part of the college experience, can rarely be achieved unless those goals have the visible and constant support of campus leadership. It further asserts that

the strength and success of enlarging global dimensions of the college experience will depend on the expressed commitment of the campus leadership. Administrative responsibility needs to be made highly visible. (Task Force Statement, 1981)

In "A Study of the Dynamics of the Interinstitutional Cooperation for International Education Development (1971)," D. S. Hoopes, a member of the Pittsburgh Regional Council for International Education, has found that the effectiveness of international programs depended on support by the institution's top administrative leadership (Burn, 1980b). Burn, in her work, Expanding the International Dimension of Higher Education, reached an identical conclusion when she 
argued that to become a major priority, international education must enlist coordinated support at all levels, and that institutional and national leadership must recognize and articulate this priority and match rhetoric with resources. Wesley Posvar, chancellor of the University of Pittsburgh, expressed the same.thought in 1980 when he stated that the first element of any strategy for expanding international dimensions must be interest and commitment at key levels of administration (Posvar, 1980).

Evidence seems to indicate that administrative sanction is essential if a new program at any college or university is to be started successfully, and no new program will strive and persist unless there is enthusiastic support based on the attitude of the leadership.

Before a scheme can be developed by any institution to begin the arduous task of gaining commitment and dedication to global awareness through education, the position and attitudes of administrators need to be assessed. Historically administrators have set the directions and attitudes of intellectual and curricular endeavors. If higher education is to meet the recommendations and suggestions of the various committees studying the nation's need for global awareness and knowledge, then it is imperative to know how to identify administrators who will pursue and accomplish this task.

Thus an attempt to understand administrators' worldmindedness attitudes and the relevance of their family, 
personal and educational backgrounds to those attitudes, will enhance the states and nation's ability to meet the needs of a growing interdependent world.

\section{STATEMENT OF THE PROBLEM}

Before an effective worldmindedness program can be established in institutions of higher learning, administrators' attitudes toward such a program must be determined through research. Just as a person's attitudes toward nationalism/internationalism can indicate strongly that person's response to government policies and actions affecting other nations, so also are administrators' attitudes firm indicators of their interest in higher education's implementation of worldmindedness programs (Shaw \& Wright, 1967). (The word "internationalist" is used in the sense of creating human internationalism comprising all human beings regardless of nationality, religion, political party, race or class.)

Latitudinal studies by social psychologist Llewellyn Queener correlated international attitudes with certain variables found that a person is more likely to be an internationalist if the parents are internationalist in thinking, if one or both parents were born abroad and if college curriculum studied was social sciences and the humanities (Queener, 1949, Vol. 29). Holger Iisager cites a study that found that groups who were exposed to some international awareness showed the greatest amount of change in 
attitude. This study consisted of a series of experiments on international attitudes with 11 groups of students and adults who were influenced in various ways, ranging from a lecture to a summer abroad. Iisager found that students who lived in an international community showed the greatest changes toward internationalism (Smith, 1955). Wallace Edgerton, president of the Institute of International Education, has stated that by promoting an awareness of the shared nature of most human concerns, international exchanges have contributed greatly to international understanding and have served as an unparalleled means of gaining the appreciation of other cultures.

In his view, foreign exchange programs engender a more sophisticated, differentiated, and personalized knowledge and perception of the host society, its achievements and problems, peoples and policies, and ways of life, as compared with "knowledge" and images held before. He believes that this new awareness has usually reduced the previously held ethnocentric stereotypes, has brought on a greater understanding and awareness of the diversity of groups and a heightened continuing interest in events, and has resulted in publications about the former host country (Edgerton, 1976).

Michael J. Flack, president of the International Society for Educational, Cultural and Scientific Interchanges, has reported that there is convincing evidence 
that in the realm of attitudes, exchanges produce people with a more realistic perspective, a more analytical and differentiated capacity to view their own society as well as others (Hoilland, 1976).:

Developing a sense of national identity begins sometime between 7 and 10 years of age, according to Swiss learning theorist Jean Piaget. Not until the age of 10 or 11 do children conceive of their nation as a distinct entity (Remy, 1975). The period from about 8 to 13 years of age may be unique in that it represents a time before too many stereotypically rigid perspectives dominate children's views of the world, and yet a time in which cognitive development is sufficiently advanced to make a diversity of viewpoints accessible.

The experience of learning a foreign language may also broaden one's appreciation of other cultures. This historical approach has recently been endorsed by the 1975 Helsinki Accord. One of its provisions states that:

to encourage the study of foreign languages and civilizations as an important means of expanding communication among peoples for their better acquaintance with the culture of each country as well as for the strengthening of international cooperation. (Final Act, 1975)

Learning another language gives insights into one's own culture and enables one to understand other cultures in ways otherwise not possible. It opens the door to the thinking and societal and cultural values of other cultures and peoples. It makes possible a better understanding of 
the wider world which increasingly impinges on their lives (Thompson, 1980).

Posvar, a former Rhodes Scholar, stresses the discovery of insight, respect, intellectual humility, knowledge of values and manner of thinking that are the end results of learning to communicate in a foreign language (Posvar, 1980).

\section{THE RESEARCH QUESTIONS}

Any number and variety of experiences with foreign travel and study may engender an interest in worldmindedness. Therefore, this study will investigate the effects of these variables--in terms of education, experience and demographics--on administrators' attitudes. One goal of the study is to recognize the significant correlations between past experience and present global attitudes. A secondary goal is to see if there are recognizable differences between the administrators of the three types of institutions that were studied--community colleges, private four-year and state four-year institutions.

The investigation was conducted in 21 institutions of higher education in the state of Oregon and was concerned with the following research questions:

1. In what ways do factors of age, sex, ethnic background, education, and socio-economic background relate to the attitudes as measured by the World-minded scale?

2. Does exposure to selected variables* influence 
the administrator's view or perception of viewing the world as a whole?

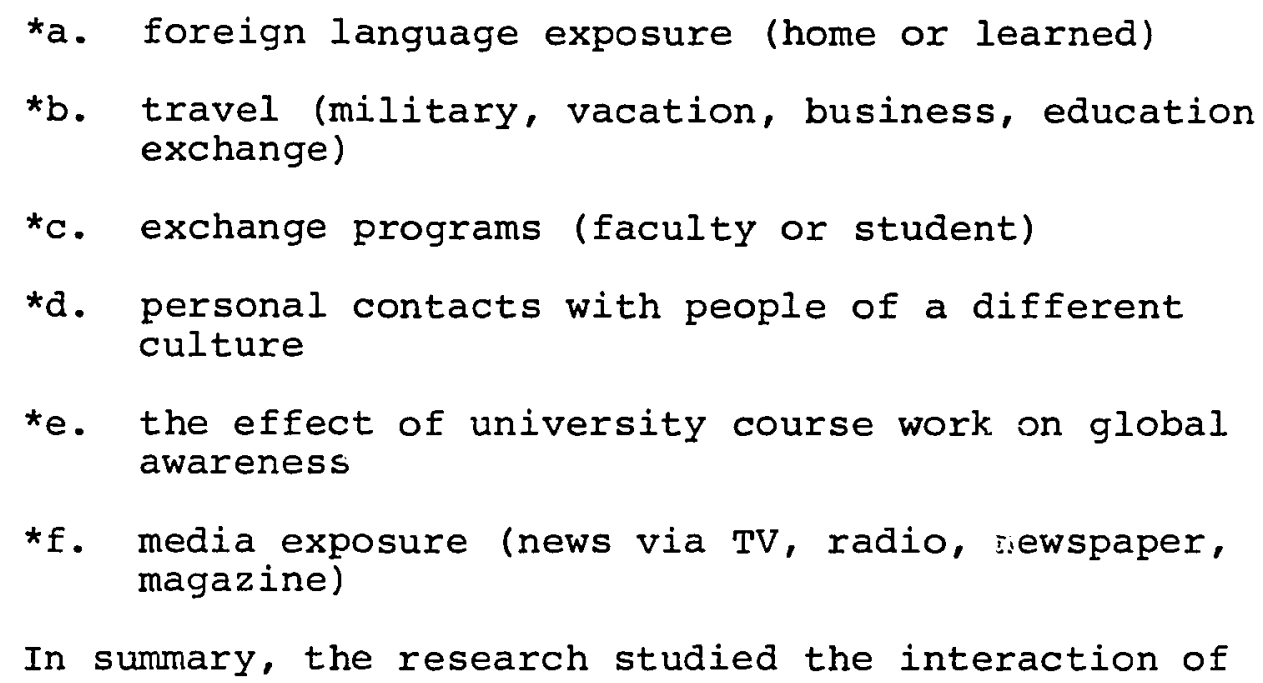
family, personal and educational background variables with the attitudes measured, and identified differences between administrators in the institutions studied as distinct subgroups according to world-minded attitudes measured.

From an analysis of these data it was hoped that inferences could be drawn regarding factors most likely to stimulate worldmindedness in persons who lack such awareness--that is, factors which influence worldmindedness in administrators. It was also hoped that a knowledge of these factors and their interrelationships would assist educators--and higher education in general--implement the government's stated directive of including worldmindedness programs in the nation's educational system. 


\section{CHAPTER II}

\section{REVIEW OF IITERATURE}

The review of literature will discuss the concept of worldmindedness, specific attitudinal variables indicated in this study, attitudes and their formation, the need for global awareness in education, and administration and the role of administrators in the diffusion process.

THE CONCEPT OF WORLDMINDEDNESS

The development of worldmindedness is an educational objective endorsed by many prominent educators (Barrows, 1980; Burn, 1980a, 1980b; Flack, 1976; Pike, 1979; Tonkin \& Edwards, 1981; Torney-Purta, 1981). But what is worldmindedness? Hanvey (1976) has declared that it is the state of planet awareness, knowledge of global dynamics, awareness of human choices, perspective consciousness and cross-cultural awareness (Strasheim, 1979).

Marker (1977) has described it as "a way of thinking about the world, which can be characterized by the notion of Spaceship Earth," that we are all in this thing together and that the fate of some of us is quickly becoming the fate of all of us (Strasheim, 1979).

Anderson (1982) has argued that it is organized 
around three principles, that students should be educated about the world in ways that illustrate that the world is a system, that it should highlight individuals as participants in the world system, and that it promote the development of competencies necessary to effective and responsible participation in the world system (Strasheim, 1979).

The term "worldminded" is generally used as an adjective to describe an individual. Conant has called the world-minded person a tough-minded idealist who has to be created, developed and educated (Kenworthy, 1952). Urso (1981) believes that the world-minded individual favors a world view of the problems of humanity, the primary reference group being humans rather than American Jews, Blacks or Germans and that worldmindedness is both cognitive and affective, providing certain abilities in that person. Those abilities are:

1. To understand and be compassionate toward those who hold different cultural beliefs, perceptions, and participate in human institutions and life situations different from their own

2. To perceive commonalities in the basic needs of culturally different social institutions

3. To define and develop one's own potential, not only for one's own benefit, but for the benefit of the human family

4. To realize and fulfill one's individual responsibility to the rest of the human family--that is, to develop 
a sense of involvement in, and sensitivity to the problems and needs of humanity, and

5. To recognize the complexity and variety of human thoughts, desires, and activities, see how these affect group and national relations, as well as the "climate" of the planet as a whole.

Kenworthy (1952) has stated that if in the years ahead educators are to concentrate on the development of world-minded individuals, then desired characteristics of such a person should be made clearer. Unfortunately, there has been little investigation in this area. Some help may be garnered from the recent studies of psychologists, social psychologists, ethnologists, cultural anthropologists, and colleagues in other related social sciences. Within the last few years researchers have delved into the formation and change of attitudes, located factors which create social politicalization and sought to understand the motivations and actions of individuals of different cultures.

Chisholm made a start on describing such persons when he wrote:

In order that the human race may survive on this planet, it is necessary that there should be enough people in enough places in the world who do not have to fight each other, who are not the kinds of people who will fight each other, and who are the kinds of people who will take effective measures whenever it is necessary to prevent other people fighting. (in Kenworthy, 1970, p. 24)

Creating such "effective measures" to avoid destruc- 
tive confrontations, in the context of worldmindedness, may be a major project of the educational process. Piaget has asserted that

The principal goal of education is to create men who are capable of doing new things, not simply of repeating what other generations have done--men who are creative, inventive, and discoverers. (in Kenworthy, 1970, p. 24)

Other attempts have been made to describe more thoroughly the characteristics of worldmindedness. The following statement was prepared shortly after world War II by a group of American educators speaking on behalf of the National Education Association. The world-minded American:

1. Realizes that civilization may be imperiled by another world war

2. Wants world at peace in which liberty and justice are assured for all

3. Knows that nothing in human nature makes war inevitable

4. Believes that education can become a powerful force for achieving international understanding and world peace

5. Knows and understands how people in other lands live and recognizes the common humanity which underlies all differences of culture

6. Knows that unlimited national sovereignty is a threat to world peace and that nations must cooperate to achieve peace and human progress

7. Knows that modern technology holds the promise of solving the problem of economic security and that international cooperation can contribute to the increase of well-being for all men

8. Has a deep concern for the well-being of humanity

9. Has a continuing interest in world affairs and devotes himself seriousiy to the analysis of international problems with all the skill and judgment he can command

10. Acts to help bring about a world at peace in which liberty and justice are assured for all. (Kenworthy, 1970, p. 25) 
Tewksbury (1948) drafted a more detailed statement

for his students. He said the world-minded person is:

1. One who has deep, active, and successful roots in one's own culture

2. One who has examined objectively the strengths and weaknesses of his own culture

3. One who is eager to consider seriously what other peoples think of his culture

4. One who is not too sensitive about criticisms of his own culture

5. One who is able in traveling to identify with other people and to listen and learn from them

6 . One who is not afflicted with a "plumbing complex" toward people in technologically underdeveloped countries

7. One who has experienced and passed beyond the stage of "cultural shock" in relation to cultures which differ sharply from his own

8. One who has personal and friendly relations with a number of persons from other countries on a long-term basis

9. One who has international friends in one's own specialized profession or occupation

10. One with whom persons from other countries can be frank and in whom they may have confidence

11. One who can discuss other cultures without bringing in name-calling, stereotyping, and extreme categorizing

12. One who has found "multiple securities" in many countries as well as primary security in one's own country

13. One who is actively concerned with promoting the exchange of contributions between one's own and other countries

14. One who is able to discuss the Soviet Union and Communist China calmly

15. One who is thoroughly familiar with and actively supports the United Nations and its specialized agencies

16. Ore who is an active member of at least one of the thousand private international organizations at work in the world

17. One who has examined his own motivations for being international-minded, and also the nature of his internationalism

18. One who has an elementary familiarity with the family of languages and sees his own language as one member of this family

19. One who does not wish to make over other peoples and cultures in his own image 
20. One who can for the moment become another person and enter empathetically into the thoughts and feelings of other people

21. One who finds it natural and satisfying to live as a member of the "family of man" because he has experienced the common bonds that unite people of different cultures. (in Kenworthy, 1970, p. 22)

Many global education enthusiasts also have contended that children should develop a disposition which reflects a positive regard for the world community and for the American nation. In their Global Dimensions in U.S. Education: The Elementary School, Torney-Purta and Morris (1972, p. 15) have written: "A balanced positive national feeling can serve as the basis for a flourishing international orientation" (Newman, 1977, p. 144).

Kenworthy and $\mathrm{zimmerman}$ have echoed the same sentiment: Loyalty to the international community should not supplant loyalty to the nation; it should supplement it. And loyalty to the international community should not contradict loyalty to the nation; it should complement it (1970). Zimmerman (1946) has said,

A person not rooted in his own culture is not only useless but mischievous, for he is constitutionally incapable of entering into that which is the deepest element in all political and social experience--the attachment of a people to its home, its traditions and its institutions. (p. 14)

Self-Concept and worldmindedness

Whether a rational, responsible type of nationalistic patriotism is compatible with the ongoing development of a world-minded disposition is arguable. It seems at least possible, however, that just as a positive attitude toward 
oneself is usually held to be necessary for the development of a positive attitude toward others, so an appreciation of one's own nation may indeed be a necessary prerequisite for world-mindedness. The literature in the area of political socialization points out explicitly that a host of social and cultural factors determine attitudes toward one's own country (Newman, 1977).

An expansion of these ideas are found in the literature (Kenworthy, 1952; Allport, 1954; Newman, 1977) in that the world-minded person is an integrated individual. Initially, this characteristic may seem far removed from the subject under discussion, but it is really the heart of the matter. The integrated individual is the aim of all education, including education for worldmindedness. The world-minded person is an expert in democratic human relations. President Franklin D. Roosevelt expressed this idea in the Jefferson Day speech he wrote, just before he died, declaring that "today we are faced with the preeminent fact that, if civilization is to survive, we must cultivate the science of human relations" (in Kenworthy, 1952). Worldmindedness connotes the worth of the individual and the belief that all persons have a contribution to make to the world community, whether it be large or small.

The Preamble to the Constitution of UNESCO points out that

ignorance of each other's ways and lives has been a common cause, throughout the history of mankind, of that suspicion and mistrust between the peoples 
of the world through which their differences have

all too often broken into war. (in Kenworthy, 1952)

Because of this danger, the world-minded person tries to develop empathy toward other inhabitants of this world.

As Frank (1949) has phrased it:

all men, everywhere, face the same life tasks, share the same anxieties and perplexities, the bereavements and tragedies, seek the same goals in their cultures: to make life meaningful and significant, to find some security, to achieve some social order and to regulat their conduct toward values that make life more than mere organic existence. (p. 394)

Arnold Toynbee has pointed out:

The paradox of our generation is that all the world has now profited by an education which the west has provided, except. . . the West herself. The West today is still looking at history from that old parochial self-centered standpoint which the other living societies have by now been compelled to transcend. Yet, sooner or later, the West, in her turn, is bound to receive the re-education which the other civilizations have obtained from the unification of the world by Western action. (1947, p. 83)

The world-minded person generally is informed about the contemporary world scene and does not live in a vacuum. Also this person will have learned at least one foreign language.

Allport (1954) has said that empirical studies have shown an important relationship between one's philosophy regarding good and evil in life and one's disposition toward hostility. People who are afraid of life, who say that the world is a dangerous, evil place, possess much racial and religious prejudice. Consequently, they are unable to be world-minded. A positive philosophy of life 
is essential for the world-minded individual.

For more than 30 years, the American Field Service has been selecting, orienting and supporting high school students who have chosen to live abroad in another society for a period of three months to one year. The following list of psychological factors and attitudes which form a positive framework for participation in a global society are based on the assessment areas used by the American Field Service International/Intercultural Programs (AFS Student Selection Handbook, 1978). These factors have proven to be important in the students' capacity to cope successfully in a new cultural context. Taken together they represent one profile of characteristics necessary to participate in a global learning process. These students (1) have a strong sense of self-concept and have demonstrated patience and tolerance for ambiguity; (2) have the ability to accept failure and the realization that power and responsibility can be shared; (3) are knowledgeable about their own strengths and weaknesses, and have a sense of humor, and (4) have the ability to be objective about one's circumstances. The AFS believes that these four characteristics are important for participating in the global learning process. They form the underlying network of capacities and skills necessary for individuals to contribute effectively to an interdependent world. To summarize what the world-minded person is, I 
submit the following: This person has become or is becoming an integrated individual, skilled in the art of human relations and conscious of the wide variety of behaviors in the world, rooted in family, country and culture but, at the same time, able to identify with the people of other countries and cultures. Informed about the contemporary world scene, the world-minded individual is concerned about improving the conditions of the human family. Buttressed by a positive faith or philosophy of life whose basic tenets can be seen in a universal sense, the worldminded person believes that global cooperation and education are desirable as well as possible and wants to promote them.

Clear about educational goals for worldmindedness, this person as an educational administrator will be conversant with methods and resources for such programs and will be able to help create worldmindedness in faculty and students.

Perhaps these abilities seem overwhelming and even impossible to attain. Yet, it is acknowledged in much of the literature that if mankind is to move toward a future of world peace and understanding, these abilities must be fostered.

Thus researchers need to become concerned with how such abilities can be attained, how worldmindedness can be developed, and in particular, how worldmindedness can be diffused within the educational system. It is in the hope 
of beginning to provide answers to these questions, via the attitudes of administrators in the state of oregon, that this study is offered.

\section{THE VARIABLE OF STUDYING A FOREIGN LANGUAGE}

Although it is generally accepted by the foreign language teaching profession that the study of a foreign language is of considerable value in developing knowledge of and sensitivity to other countries and cultures, there is little research or empirical data to support such an assumption (Roskens, 1980). Too often educators consider language the object rather than the medium of learning. An old Czech proverb sums up the direction that language learning should be intended to take: "Learn a new language and get a new soul" (Roskens, 1980, p. 178).

The Helsinki Agreement (1975) statement regarding foreign language study is in part as follows: civilizations as an important means of expanding
communication among peoples for their better acquain-
tance with the culture of each country, as well as
for the strengthening, international cooperation. . .
(Pike \& Lewis, 1979) As laudable as the Helsinki Agreement is in supporting the study of foreign language, the statement makes assumptions about communication between persons of different cultures that deserves investigation. Torney-Purta (1981) has cited one such investigative study. In 1968, 45 American children were interviewed about 
human diversity. When asked how other countries differed from America, they frequently answered that those in other countries speak other languages, "talk differently" or "didn't talk right." These responses give both indications of egocentrism and suggestions about the importance of research into what would be considered the connection between learning to speak a second language and acquiring a global perspective (Torney-Purta, 1981).

From the outset of the Educational Testing Service (ETS) study, it was hoped that variations in student characteristics and experiences would be associated with varying levels of global understanding. Although cause and effect would generally be impossible to establish, it was hoped that some of the associations would suggest changes in the college experience that might serve to enhance global understanding.

A primary hypothesis in this regard grew from the commonly expressed opinion that foreign language study and proficiency are of considerable value to the student in developing a knowledge of and sensitiveness to countries and cultures other than his own. Exhaustive analyses of the resulting data have revealed that there is no appreciable relationship between global knowledge and foreign language proficiency. On the other hand, the effective component of global understanding associated with foreign language proficiency and language learning is history, 
at a moderate degree. Thus there may be a causal or contributory relationship between foreign language and affect (Barrows, 1982; Torney-Purta, 1982).

The problem of the exact relation between language and thought has been the subject of considerable discussion by psychologists. The behaviorist watson has even gone so far as to regard them as identical. In his view, thinking is merely speech which remains subvocal (Phillips, 1977a).

There can be no doubt that thinking, in the large majority of cases, does require the use of language and that the nature of language has an important influence on the nature of thought. Sapir has pointed out that the forms of our language predetermine for us certain modes of observation and interpretation (in Klineberg, 1950).

It may be that language determines thought. It may also be that the thinking of the people and the problems which interest them determine the form and character of the language. It is likely that an interest in certain problems or objects develops a vocabulary capable of dealing with them adequately; but it is also likely that an individual born into any particular culture will think in terms of the medium of expression current in his society, and that the nature of his thinking will be affected thereby (Klineberg, 1950).

Differences in the vocabulary of peoples tell us something about their cultures. It is significant that 
more words for philosophical and religious thought are to be found in Indian literature than in Greek, Latin and German languages combined. In some languages it is not possible to differentiate between "to kill" and "to murder." The distinction we make in this regard is based on a certain legal philosophy which considers intent or motivation to be an important aspect of the act. Other societies emphasize the result that someone has been killed. Another example is that there are 6,000 names connected in some way with the Arabic word "camel." This reflects the importance of the camel in the Arab civilization. In the same manner, this large variety of words for "snow" in the Eskimo language reflects the Eskimo need to address that particular phenomenom carefully.

Another type of linguistic distinction is demonstrated by the use of a suffix in the Hupa language that is added to indicate the statement's source of authority--i.e., perceived by hearing, an occurrence has been seen, and conjectured from circumstantial evidence (Klineberg, 1965).

At a somewhat more complex level, the emotinal vocabulary of contemporary nations has sometimes been interpreted as furnishing clues concerning prevailing national attitudes. For example, there is no single word in English to translate adequately the frequently used word in German to describe the relationship of a German boy and his father--"Ehrfurcht"--which combines the ideas of honor, 
respect and fear.

In general, it may be concluded that language and thought are intimately related and mutually influence each other. The vocabulary in particular can give us valuable information as to the content and interests of the culture. Language serves as an instrument of thought and communication as a means of controlling the actions of others, and a force which unites the members of a particular community and at the same time separating them from others. This is the principal motivation for movements which have developed in support of Esperanto and other international tongues as a means of uniting human beings worldwide. There is no doubt that language can act either as a cohesive or divisive force, depending on the degree of understanding. Another difficulty rarely recognized arises from the need to conduct most international negotiations through translation. Even the best interpreters in the world will occasionally be faced with complex problems of communication. There may be exact equivalents for the terms used, but the translation may be misleading if the word has different connotations in the two languages because of varying cultural and historical frames of reference. Democracy, freedom and peaceful coexistence are examples. A slightly different kind of difficulty of meaning is represented by the verb "to compromise." The word has two distinct meanings in English and French, but the first meaning in 
the one language is secondary in the other, and vice versa. In English, compromise means to adjust and settle by mutual agreement, and in French, to expose, to endanger, to embarrass, losing one's reputation, compromising someone. It is easy to understand the unpleasant reaction of a French mind when the suggestion is made "to compromise" (Klineberg, 1965).

Much more serious in its effect on international relations was the case of the oft-quoted Khrushchev remark, "We will bury you." This has usually been interpreted in its active sense, that is, "We will destroy you." Actually the translition is correct in the sense that "We will outlive you" or "We will still be alive when you are dead" (Bronfenbrenner, personal communication). In other words, it expresses the conviction that communism will outlast capitalism, not that the communists will violently destroy the West (in Klineberg, 1965, p. 153).

Language is an integral part of a national culture and problems of communication are intimately involved in the material related to the characteristics of nations. Harvard and several other colleges and universities have asserted the necessity of integrating foreign languages in undergraduate instruction. Harvard's newly adopted core curriculum states:

An educated American, in the last third of this century, cannot be provincial in the sense of being ignorant of other cultures and other times. It is no longer possible to conduct our lives without 
reference to the wider world within which we live. A srucial difference between the educated and the uneducated is the extent to which one's life experience is viewed in wider contexts. (Roskens, 1980, p. 176)

Learning another language enhances verbal skills generally, gives insights into one's own culture, and enables one to understand other cultures in ways otherwise not possible. It opens the door to the thinking and societal and cultural values of other cultures and peoples. It makes possible a better understanding of the wider world which increasingly impinges on their lives (Perkins \& Burn, 1980).

Iinguistically, interdependence stresses the give and take of real communication. Foreign language is a vital connection in the interdependent relationships of the next century, since true interaction can occur only where each community experiences the language and lifestyle of the other, where no group achieves dominance by imposing its language structure on the other (Strasheim, 1979).

The President's Commission on Foreign Language and International Studies indicates that one American in six owes his or her job to foreign trade and that Americans lose out on 100,000 jobs a year because they do not know a second language (Roskens, 1965).

The study of foreign language has suggested analysis of the psychology of understanding language, another facet of the communication process. In developmental psychology 
of recent years, for example, there has been considerable study of fields known as meta-cognition, meta-memory, and meta-linguistics. These are defined (respectively) as the individual's verbalizable knowledge about the processes of thinking, remembering and speaking. Students are interviewed, for example, about how they believe they go about generating or understanding language. Exposure to second language instruction may be the enhanced ability to take more fully the perspective of someone who does not speak English (Torney-Purta, 1981).

Magrath (1982) believes that international education and foreign language instruction at all levels of American education are so weak and so underfunded that fundamental American security interests are being jeopardized. He has proposed a new federal commitment that initially would make one-half billion dollars annually available to meet this need. The question raised is: do enough people care so that action can be taken? Magrath's fundamental conclusion is that our lack of foreign language competence diminishes the nation's capability in diplomacy, in foreign trade, and in citizen comprehension of the world in which Americans live and compete. He feels it is the duty of educators to make the American public aware that the United States can no longer afford to be monolingual.

If teaching a foreign language is simply skill development in another language, then worldmindedness and lan- 
guage study have veiry little in common. But if the emphasis is upon the way language and culture interact and influence the way one sees the world then there is a commonality (Strasheim, 1979).

THE VARIABLE OF FOREIGN EXCHANGE

It is a common assumption that getting to know the people of another country will lead to liking them; this assumption underlies the expectation that exchange-ofpersons programs will increase international goodwill. This hypothesis would lead one to expect that, on the whole, visitors to a country will leave with more favorable views than they held before their arrival. The entire body of research suggests that this expectation is oversimplified.

In order to assess more realistically what effects the cross-cultural experience is likely to have on attitudes toward the host country, researchers need to think more analytically (Caello, 1962).

Kilpatrick says, "We learn what we live" (in Beauchamp, 1953). But it seems certain that in a large number of instances the nature of one's experience with members of another group will be determined by the pre-existence of an attitude, rather than the attitude being determined by the experience (Klineberg, 1954). Kelman (1962) suggests from his findings that despite limitations, international cooperation and exchange are likely to contribute, at least indirectly and in the long run, to creating the conditions 
for peace.

Combs cited four types of effects of international cooperation and exchange that may have an impact on the relations between two nations and may reduce the likelihood that conflict between them will take violent forms:

1. an increased openness, among key individuals in each nation, in their attitudes toward the other nation

2. a reduction in the level of tension between the two nations

3. an increase of commitment to an internationalist ideology

4. a development of a network of relationships cutting across national boundaries. (in Kelman, 1962, p. 2)

The atmosphere of the home is as important, perhaps more important, than the parents' specific teaching concerning minority groups. Instruction of the sort that involves the whole person in intercultural activities is probably more effective than merely verbal learning or exhortation. While information is likewise essential, facts stick best when embedded in the soil of interested activity (Newcomb, 1954). Therefore, close attention must be given to providing students enhancing contacts with nationals of the host country (Hensley \& Sell, 1979).

Flack has stated that few concepts in the area of general discourse on social policy are more frequently used, yet more difficult to analyze, identify and prove than results, effects or impacts. The effects of education and of person experiences involve particularly vexing and complex problems (1976). 
It is important to learn what are the conditions, effects, and results of international exchange experience and learning if for no other reason than because in a variety of forms and methods they will represent a growing imperative in preparing persons everywhere for constructive functioning in an increasingly interdependent world. Also, emphasis on evaluation of results may in time lead to more deliberate and comprehensive research as to the factors that enter into and affect the dynamics of intercultural learning, encounters and of their role in the development of world-minded attitudes.

Analysis of results of study abroad confront serious problems. Among them, two appear to be central (Flack, 1976): First, an inclination to assume the effects on an individual to be specifically owing to the sojourn abroad; and second, an inadequate differentiation and articulation of the concept of results itself. In other words, of what, on whom, on what, due to which influence, time frame, age factor and combinations of the above. As of yet, this complex a study has not been developed and researched. Spaulding and Flack (1975) formulated an overview on foreign students between 1967 and 1974, supplemented by some pertinent earlier studies by Cournack, 1962; Cussler, 1962; U.S. Department of State, Bureaus of Education and Cultural Affairs, 1965 (in Spaulding \& Flack, 1975). The overview yielded the following profile of functionally rele- 
vant findings on the effects on the individual:

1. Improvement of competencies in foreign language yields benefits in personal and professional life.

2. The experience and awareness of alternate or additional models of social institutions, roles, behavior and values yielding a greater resourcefulness in the realm of social diagnosis, innovation or invention.

3. The establishment during the sojourn of acquaintances and relationships with the host country. Unless nurtured, such relationships tend to subside.

4. In the psycho-social realm, the sojourn and educational experience tend to engender a more sophisticated personalized knowledge and perception or the host society, its achievements and problems, its people and policies and its ways of experience as compared to previously held images. This usually reflects itself in a reduction of ethnocentric, stereotyping and a greater understanding.

5. A heightened, growing, continuing interest in events, developments, publications about a general news from or about the society of former residence (p. 108). Necessary to planning a global education program is the researching of opinions and an attempt to discover the basis of those attitudes. Such research can be used to plan educational programs more effectively. "Since wars begin in the minds of men, it is in the minds of men that the defenses of peace must be constructed" (UNESCO Preamble). 
Sellitz and cook (1962) noted that few studies of foreign students have been able to ascertain their preconceptions of the host country before their arrival in it. Research has not shown whether people who arrive with certain kinds of preconceptions are more likely to undergo changes than others.

The problem is complicated when visitors bring with them not only preconceptions about the host country but also a variety of motivations that influence the extent to which the experience can lead to changes in their attitudes (Sellitz\& Cook, 1962).

Differences in national background seem to be a major source of differences in perception of the host country (Lambert, 1956).

Hensley and Sell's (1979) analysis indicates that a substantial degree of change occurs only on the variable of self-esteem, with students tending to increase their level of self-esteem. Their findings were in response to the Kent State University Geneva Semester Program to determine if there was any change on worldmindedness, support for the UN and self-esteem. Hensley and sell were interested in testing a hypothesis suggested by social-psychological theory that attitude changes would be significantly related to two key independent variables, closeness of contact with non-Americans and overall enjoyment of the overseas experience. Their results support the view advanced by Smith 
more than two decades ago:

What a person's general attitudes will be after such a heterogeneous experience as being in another country is determined more by what his attitudes are like before he leaves home than by what happens to him while he is away. (Smith, 1955, pp. 474-475)

Hensley and sell did find evidence that the variables of enjoyment of the experience and contact with non-Americans did have some effect upon the psychological attitudes studied. Their analysis showed that the extent of contact with non-Americans is a more important factor in attitude change, although the impact is on psychological and not political attitudes.

Results of studies undertaken thus far have established that positive developments do not occur automatically in overseas educational programs. If such programs are to have validity, it seems clear they must be founded on solid curriculum and led by persons with a positive self-concept.

\section{GLOBAL AWARENESS IN EDUCATION}

If positive attitudes about self, nation, different cultures and life are prerequisites to a world-minded attitude, then it is imperative to understand how attitudes are formed and/or change in these areas.

Attitudes may be regarded as having various attributes or dimensions (Hartley, 1946; Krech \& Crutchfield, 1948; Allport, 1954). An attitude is defined as a state 
of readiness for certain types of responses. It may be adopted, readymade by imitation, or it may result from personal experiences of various kinds. It is expressed frequently in the form of a stereotype or prejudice which may have a marked influence on perception and behavior. In a survey of 10,000 Lutheran congregations made by the Department for the Christian Approach to the Jewish People of the National Lutheran Council, it was discovered "that congregations which have no contact with Jews show, on the average, more undesirable attitudes than congregations which do have such contact" (Lee, 1950).

After studying the development of attitudes toward Blacks among white children in the North and South, an investigator came to this conclusion in 1936:

It seems that attitudes toward Negroes are now chiefly determined not by contacts with Negroes, but by contact with the prevalent attitude toward Negroes. (Lee, 1950)

A social psychologist gave a slightly modified form of the Bogardus Social Distance Test to some 600 students in eight eastern colleges in an effort to learn their attitudes toward each of 49 groups, including Arab, atheist, Roman Catholic, as well as names of three groups completely unknown. On the average, the college students expressed as much unwillingness to associate with these as with any of the other 46 groups (Hartley, 1946). The cause of attitudes constitutes a problem of fundamental importance in connection with methods of 
attitude change (Klineberg, 1950). How do attitudes of friendliness or unfriendliness develop? What are their sources and on what experiences are they based? Allport (1954) has suggested that four common conditions are mainly responsible. There is, first, the accretion of experience. Second, there is what Allport calls "individuation, differentiation or segregation" (p. 136); that is to say, further experiences make the attitude more specific and distinguish it from other related attitudes. Third, trauma or dramatic experience has a strong impact. And fourth, an attitude may be adopted readymade by imitation of parents, teachers, peer groups and work associates.

An interesting study by Hartley (1946) reported that when an attitude of unfriendliness toward foreigners has developed, it is extended indiscriminately to all groups. He also found that there is evidence to suggest that the degree of tolerance expressed by individuals is a generalized function of the individual and is not necessarily determined by the group toward which the attitude is directed (Klineberg, 1950).

Most attitude theorists do seem to agree that the term attitude refers to some aspect of an individual's response to a given social object or class of social objects. It has also been generally agreed that this response can be considered in terms of three components: one's belief about the object, the degree of positive or negative effect or feeling one holds toward it, and one's actual behavior 
toward it (Lemon, 1973; Shaw, \& Wright, 1967). Fishbein and Ajzen suggest a fourth component--one's behavior intentions with respect to the object. Most attitude theorists also agree that attitudes are learned and thus can be changed, and they are relatively stable or enduring (Fishbein \& Ajzen, 1975; Lemon, 1973; Shaw \& Wright, 1967). Shaw and Wright offer this definition of attitude: A relatively enduring system of evaluation, affective reactions based upon and reflecting the evaluative concepts or beliefs which have been learned about the characteristics of a social object or class of social objects (Phillips, 1977a). All attitudes incorporate beliefs but all beliefs are not part of attitudes (Krech, 1948).

Theoretically, a society could be completely made over in something like 15 years, the time it takes to inculcate a new culture into a rising crop of youngsters. But such a theory assumes that parents and teachers have all been re-educated themselves (Chase, 1948).

There is a dearth of studies about attitude formation toward other nations and people. Few studies were found by the researcher that deal with pre- and post-exchange attitudes. The literature does contain a plentiful selection of studies concerning foreign students in America. But as this review has pointed out, attitudes are formed within a particular environment or situation, and as Kelman (1970) has suggested, the attitudinal change that occurs also 
reflects the status of the person in the host country. Studies have shown that the Scandinavians fare more positively in the United states due to similarities in culture than do Indians from an Eastern culture (Kelman, 1970; Sellitz \& Cook, 1962). Consequently, an American exchange student or teacher will experience a very different set of attitudinal changes in Teheran than in London.

An important study of attitude formation toward other nations was conducted by Lambert and Klineberg in the late 1950s. Three thousand, three hundred children at three age levels $(6,10$ and 14) from 11 parts of the world were interviewed. Among the most important research questions were those aimed at finding out whether children perceived a country as similar or different from their own.

The study found that by age 14, children were much more likely to focus on political characteristics. In the United States children at all age levels appeared to be high in their liking for foreign persons. Of special interest is the author's conclusion that American children of about 10 years of age were particularly receptive to approaches of foreign people and were interested in people who are seen as dissimilar to themselves as well as those who are similar. By the age of 14 American young people were much less open to positive views of foreign nations. There was further evidence that from about the age of 10 , children begin a process of stereotyping people (Klineberg, 
1970)

Targ (1970) and Rosell (1968) have reported that by early adolescence children have developed a host of beliefs, values, attitudes about the world and about international politics. Mortenson's (1976) study verifies that attitudes toward culturally different children can be changed but only through having contact with such children, not just through intellectual discussion and reading. Conclusions were that students who were taught courses without having real life experiences with them become more prejudiced. Students who worked with minority people became less prejudiced in general.

The largest, second most recent United States study of concepts and attitudes in this area is "Other Nations, Other People" (Pike, 1979). The study consisted of 550 to 600 students at grades 4,8 and 12. A total of 1,728 students from 27 states were surveyed. There were also 315 social studies teachers surveyed about interests and backgrounds.

Pike observed that outside of regular course work, television and reading were clearly perceived by students at all three grade levels as having the strongest influence on their thinking, attitudes, and opinions with respect to other countries and peoples. Movies, teachers, travel, relatives and friends ranked in varying order for next most important. 
The attitudes of male teachers indicated that they gathered their knowledge about other nations and people in order of vacation, education, reading and military travel. Their attitude acquisition was through foreign friends, interests, reading, friends and vacation. The female teachers ranked slightly differently in knowledge gathering. Vacation, higher education, foreign and other friends and attitude acquisition was the same (Pike, 1979).

In summary, there have been a number of studies of children's reactions to and knowledge of other nations. This includes both research in the United States and Europe. Most of the research has focused on selective bias in the acquisition of information of attributes or characteristics and on ways in which young people group or categorize nations.

In 1980 freshmen and seniors in four-year colleges and students in two-year institutions were surveyed nationally to determine their understanding of the world and world issues. The survey, sponsored by the Council on Learning and a national task force, was based on a sample of about 3,000 undergraduates at 185 institutions. It included a test of global understanding and three questionnaires on backgrounds and proficiency and their attitudes toward foreign nations and world issues.

The Educational Testing Service survey design called for developing measures of four presumed components of global understanding: (1) background, experience and 
interests; (2) foreign language training, ability and attitudes; (3) knowledge, and (4) affect (attitudes, interests, values).

How background, language and attitudes correlate with performance on the knowledge test and how closely are students' backgrounds, language proficiency and feelings about other peoples and cultures associated with their knowledge of the world about them were questions addressed by this study.

Taken together, the Educational Testing Service survey results indicated that global understanding is not a single entity but must be thought of as having three principal components: knowledge, affect, and language. The knowledge factor was defined primarily by scores on the knowledge test as well as a habit of acquiring international news through news reading. Affect was defined largely by several attitudinal measures that are predominantly, but not exclusively, political in nature. The language factor was defined by foreign language abilities, learnirg experience, and attitudes toward foreign language study (Barrows, 1982).

Among the various background variables surveyed, only race and education of parents were significant. Both related strongly to socioeconomic status, which in turn was closely associated with educational achievement. Not quite as strong but nevertheless significant was the correlation 
between the education of the students' parents and the way students in the three groups performed on the test. The more education the parents had, the higher the score their children earned. Lentz (1950) also found this to be true. Those students who reported that they are regular readers of international events in newspapers and other print media consistently scored higher on the test than those who acquire their information from television or radio news programs. Pike and Barrows found that television (61\%), periodicals (50\%), travel (25\%), parents (24\%), and teachers (328) influenced attitudes and opinions toward other nations and peoples of 12 th graders.

Among the attitude results was a high correlation between students' liberal political orientation and scores on the knowledge test. Those students scoring high on the test favored a concerned, cooperative, pro-world government, pro-human rights, anti-war and anti-chauvinistic sentiments measured by the survey's attitude scales (Barrows, 1981; Lentz, 1936). This finding is consistent with studies done by Allport (1954). Barrows (1581) noted that affect is moderately associated with both language proficiency and knowledge.

A second major conclusion observed repeatedly in the survey's results was the correlation between the way students acquire information and their knowledge affect about attitudes toward global understanding. Reading newspaper 
articles, especially international news articles, and frequency of newspaper reading were closely related to a cluster of correlates of knowledge and affect. The relationships may indicate that international news in newspapers is the most informative source or that these articles are only turned to by persons whose interest and motivations are already high. The additional effort required by newspaper reading over passively responding to the electronic media suggests the latter explanation.

It is interesting to note that history majors excelled on the test, achieving a mean score of 59.30 . Their colleagues specializing in the other social sciences scored above the mean (52.77), but they were outdistanced by engineering and mathematics majors, 53.2 and 54.07 respectively. Particularly disquieting was the lastplace finish of education majors whose mean score was 39.83. Language majors scored just barely below the mean $(50.22)$.

EDUCATIONAL OBJECTIVES FOR GLOBAL AWARENESS

What is the educational objective for creating worldminded individuals? It seems that the basic need is to communicate the way of life of different peoples to one another so as to achieve three objectives:

I. An appreciation of the common human qualities underlying cultural differences

2. An understanding of the central values of other cultures 
3. A realization that the value systems of the world's peoples are each compatible with the universal human qualities even when not compatible with each other. (Scanlon, 1960, p. 190)

Wells said education is a race for survival (in Reinhardt, 1980). It provides an insight into the limitless creativity of the races of the globe. It remains diplomacy's greatest asset in cooperative efforts toward the resolution of the complex problems of the world. Reinhardt has said that education springs from a conception of truth. It will not be confined within geographic boundaries and cannot be contained exclusively in one political or cultural philosophy (Reinhardt, 1980).

If education reaches beyond boundaries, it also must be accommodative and multi-faceted. The American educational system has been described as unusually flexible, pragmatic and adaptable. Thomas Jefferson wrote in 1779 of "education adapted to the years, to the capacity, and the condition of everyone and directed to their freedom and happiness" (in Reinhardt, 1980, p. 2). Key (1980) wrote that education should provide students a multi-layered outlook. He said that as individuals and as democratic citizens, Americans need a sense of the total picture--that is, perspectives that are personal, local, national and global all at the same time (in Pellicano, 1981). Education can encourage the acquisition and development of such perspectives.

The phrase global education is a code word to express 
a specific type of perspective, therefore global (macro perspective) and that the organization and transmission of knowledge and values is such that knowledge is not overly specific and particularistic (Pellicano, 1981).

Bailyn has stated that individuals seem content to be specialists, but that somewhere somebody has got to pull it together. The point is now to draw up and synthesize. The need is for a macro view, a view that uses the details and the particulars generated and/or uncovered by the specialists to construct the broad vision and panorama that are labeled "eras, epochs, periods." This macro view is one that searches for the linkages between details and events in order to conduct a paradigm that is both interpretative and general (in Pellicano, 1981, p. 125).

A macro view also incorporates the idea of context in the global education process. American democracy is based upon the belief that every citizen should be wellinformed to be an effective member of the community. But community in the current age necessarily means the context of nation and world. Such global context, such perspective, is global (Pellicano, 1981).

The macro and micro perspectives are complementary. One without the other results in distortion and/or meaninglessness.

Hanvey (1976) has interposed the term "global cognition" for global perspective. 
In review, then, global perspective, cognition education is a macro perspective in contrast to the micro perspective which dominates the contemporary educational system in America today.

Gilliom (1981) has stated that global education in global perspective is the development of knowledge, skills, and attitudes appropriate in a world of limited natural resources, ethnic diversity, cultural pluralism, and increasing interdependence of nations, institutions and people. Global education viewed from a global perspective requires the preparation of teachers and teacher educators whose knowledge about the world and attitudes toward diversity and common human interests reflect global realities.

Brademas has said,

I believe that there is a special responsibility on the part of the colleges and universities of the United States to help educate the American people about the other people of the world. (1982)

The nation's teaching institutions and those that administer to it must play an important role in incorporating the current understanding of the global perspective into the substance of education.

Global education offers a response to the challenges posed by modern global realities. It is ultimately a goal. Its ultimate goal is not the evolution of a world community governed by a super state but the development of a comprehension of the differences and similarities within humankind, of how people's actions reflect their percep- 
tions of reality and of the concept of interdependence, global conflict, equity, and human rights.

Educators need to acquire the knowledge, attitudes and values on which global education depends. To prepare citizens for global realities, educators must first address the change in curriculum needed to facilitate the development of world-minded individuals through the nation's educational system.

The rationale for introducing global education into programs for preparation of teachers rests on several points: (1) a certainty of continuing changes, (2) the need to redress deficiencies, (3) recognition by national commissions of the need, (4) accreditation requirements, and (5) recommendations by the American Association of Colleges for Teacher Education (Klassen, 1982).

Global education is an educational effort designed to cultivate in people a global perspective and to develop in them the knowledge, skills and attitudes needed to live effectively in a world possessing limited natural resources and characterized by ethnic diversity, cultural pluralism and increasing interdependence (Gilliom, 1981). Interdependence denotes a relationship of mutual dependence. It differs from independence and dependence in its implication for a two-directional approach; one nation or culture is neither wholly a recipient and therefore dependent upon others nor toally a donor and there- 
fore independent of others (Strasheim, 1979).

At the heart of the global awareness process are human beings whose personal capacities, prejudices, experiences, attitudes and beliefs will ultimately determine the success or failure of any educational program designed to meet the needs of interdependence.

For the past three decades international education has been the generic term for most of the activities and studies dealing with foreign countries. International, however, refers to relationships between nations rather than to broader issues that embrace the world and all humanity. The latter is the province of worldmindedness and global education.

ADMINISTRATION AND THE ROLE OF ADMINISTRATORS IN THE DIFFUSION PROCESS

To bring about needed curriculum change in the nation's existing educational programs, a diffusion of the concepts and beliefs of worldmindedness is needed.

Iiterature indicates that it is the figure in authority, the administrator, who sets the pace for implementation and success.

Historically, change in American education was viewed largely as a process of "natural diffusion." That is, new ideas and practices arose in some fashion and spread in some unplanned way from school to school and 
from district to district. The result was that schools generally change very slowly: in the late 1950s Mort observed that it then took about 50 years for a newly invented educational practice to be generally diffused and accepted in schools throughout the country and that the average school lagged some 25 years behind the best practice of the time. Mort observed that there was a pattern to this unplanned process of diffusion:

Education change proceeds very slowly. After an invention which is destined to spread throughout the school appears, fifteen years typically elapse before it is found in three percent of the school systeris. - . After practices reach the three percent point of diffusion, their rate of spread accelerates. An additional 20 years usually suffices for an almost complete diffusion in an area the size of an average state. There are indications that the rate of spread throughout the nation is not much slower. (in Owens, 1981, p. 236)

The Educational Resources Information Center (ERIC) Thesaurus of Descriptors (1982) states: "The process by which an idea gets from its source or origin to its place of ultimate use is called diffusion" (ERIC, 1982, p. 66). Diffusion is the process by which an innovation is disseminated among potential users. Existing studies focus almost entirely on the diffusion of technological innovations. An interesting issue is whether the diffusion of administrative and technological innovations can be treated in an analogous fashion (Teeche, 1980).

Administration must be an active partner involved in the development process to assure that all subsystems of 
the organizational system stay appropriately linked together in a dynamic interactive way. In operational terms, organizations are hierarchical and will continue to be so (Owens, 1981).

Lambert (1980) speaks of the diffusion from Olympus down and that the grain of this idea or relationship is firmly entrenched.

To promote successful educational practices and encourage diffusion to schools across the nation, the United States Office of Education (OE) has established the National Diffusion Network (NDN). This organization is designed to bring together representatives of federal, state, and local agencies to promote the transfer of successful educational approaches both within and across state lines.

In June 1975 OE contracted with Stanford Research Institute to conduct a national evaluation of the NDN organization, processes and adoption characteristics.

The OE evaluation study revealed that characteristics of a successful NDN project implementation were:

1. Successfully implemented projects had strong local leaders and administrative support.

2. Most adoptions involved some modification of methods and materials in order to adopt the innovation to local conditions.

3. The implementation process was gradual and cumulative. 
4. Most districts viewed the project they adopted as one that satisfied a major need.

5. The study found little project dissemination activity in states without funded facilities and little dissemination or projects that were not funded for national diffusion (1977).

There is a plethora of professional literature which addresses the problem of curriculum change, its principles and prescriptions, most often dealing with the planning process. A scarce commodity is descriptive literature, based on empirical research which identifies variables potentially associated with successful curriculum change (Gress, 1979).

Gress (1979) has identified and described variables associated with successful diffusion of curriculum program change. He found that teachers as the agents of change exhibited greater professional experience and competence if they exhibited positive self-concepts and generally held positive professional outlooks. In addition, the teacher's relationship to the planning, implementation and evaluation had a positive impact.

Carlson (1962) found in a west Virginia study that the position that the superintendent of schools held in the social structure of the school superintendents of the county made it possible to make reasonable predictions about the amount and rate of innovation in that superinten- 
dent's school district. When the superintendent was looked upon as a leader by peers, as influential among other superintendents, and as in communication with many of them, their district tended to adopt innovations early and thoroughly.

Martoranna and Kuhns (1975) have advanced a design for understanding, analyzing and monitoring innovation in academic settings. Termed the interactive process theory, it emphasizes that success or failure of a new departure depends on the interplay of three sets of forces in the dynamic institutional setting: 1) the relationship of the innovation to goals set for the institution, 2) the personal forces acting either in favor of or against the change, and 3) the extrapersonal forces that bear on the innovation and its institutional setting.

Tonkin and Edwards (1981) said it would be an exaggeration to suggest that any idea initiated by the faculty cannot succeed without the support of the administration. Everything depends on the nature of the idea, the strength of the faculty support, and the attitudes of individual administrators. Nevertheless, a proposal to move toward the comprehensive globalization of an institution cannot proceed far without strong support by senior administrators (Heenan \& Perlmutter, 1979).

The number one success prerequisite for global education depends mainly on creative leadership on the campuses. 
Agency for International Development (1980) has stated that the first essential element is commitment at key levels of administrative and academic leaders (Burn, 1980c).

Given the fragmentary nature of teaching faculty, it is more likely the idea will originate with the administration. Levine and Weingart (1974) suggest that only the administration can effectively move an institution into reform, or at least that the two will hatch the idea simultaneously through good lines of communication. The best condition, then, for beginning to strengthen the international dimension of a college, is one in which there are already good lines of communication between administration and faculty and an idea originating with one can easily be espoused and advocated by the other (Tonkin, 198I).

Kenworthy (1970) referred to Marvels' 10 commandments for institutional programs for world awareness, two of which follow:

1) Do not start at all unless sufficient faculty and administration commitment exists or can be built, and

2) create a definite focal point of leadership for the institution's new efforts in global education.

No program will persist if there is not administrative sanction for it, and no program will achieve any marked success without enthusiastic and adequate administrative support (Kenworthy, 1952). Much will depend upon the attitude of the leadership of any school or college. Kenworthy (1970) in surveying the promising practices in 
education for world-mindedness has been struck by the parallelism between the interest and usually the experience abroad of the administrator and the type of program being carried on.

A similar idea was expressed by the President's Commission on Foreign Language and International Studies in its report (Tonkin \& Edwards, 1980, p. 180):

The Commission recommends that American colleges and universities demonstrate and implement their commitment to international studies and programs by centralizing them at a high level in their institutional structure. Such an international studies office would have direct access to the central administration and sufficient staff and resources to have leverage throughout the institution. It is also important that this office be broadly inclusive, so that foreign language and international studies, student and faculty exchanges, and foreign assistance projects and contracts are coordinated and mutually reinforcing rather than separate and competing. Crucial to all this is the leadership that the president of the college or university provides by encouraging and supporting international programs.

Nason (1964) stated that indispensable for a successful program are two prerequisites. One is financial resources, and the other is the clear and unequivorai institutional commitment to what has been called the international studies dimension of liberal education. Torney-Purta has reported on a recent survey of school board members and school superintendents that more than $69 \%$ believed that global education is an important idea, and $25 \%$ believed that it is "an overdue idea."

However, global education programs must complete with other important ideas for resources. Even the Council 
of Learning Project does not conclude that the reasons for such gaps is opposition to the idea (Tonkin \& Edwards, 1981).

Tonkin and Edwards have written that the effort at internationalization should itself be comprehensive, beginning with the recognition of two basic realities: first, that the academy has a responsibility to prepare people for a world radically different from that of 30 or 40 years ago, and a responsibility to study the problems of that world; and second, that we know enough about this world of today and tomorrow to build a curriculum based on a recognition of these new realities. Recognition of these realities might begin with imaginative and realistic senior administrators. For all educational institutions to make this effort, it will require the vigorous support of senior administrators and at least a persuasive group of faculty opinion-makers, the more senior and prestigious the better (1981).

The role of the administrator is crucial. Because teacher education is not a self-contained program at a college or university, incorporating a new dimension such as global education affects departments throughout the institution. Such incorporation requires broad institutional support and makes it imperative that the central administration demonstrate its commitment. For global education, this commitment may take several 
forms. A formal statement of mission and recognizing the importance of a global perspective may be published. The teacher education department may publish a separate statement of its commitment. A teacher education department may appoint and support an individual or group from the faculty to coordinate and develop activities to foster worldmindedness. And, institutions may encourage their administrators and faculties to participate in regional, national, and international programs (Baptiste, 1980). 


\section{CHAPTER III}

METHODOLOGY

\section{INTRODUCTION}

Owens (1981) has stated that management cannot presume to change the organization without being part of the process. Administration must be an active partner involved in the development process. Organizations are hierarchical, and when subordinates see that the administration is doing something to organizations in the name of improving their effectiveness--something in which administrators are not involved except as observers--the subordinates are very likely to be wary and less fully committed. On the other hand, if the administration is already interested in the undertaking, committed to it, and involved in visible ways, subordinates are much more inclined to view the effort as valid and will be more highly motivated to involve themselves.

Therefore, for global awareness to be included in our existing educational system, research of administrators' attitudes regarding worldmindedness need to be assessed, for their attitudes will be reflected in their support or lack thereof.

Research into and evaluation of intercultural and 
educational experiences that are aimed at the development of world-minded attitudes is conspicously lacking. Prior to Sampson and Smith (1957) the absence of an adequate scale to measure worldmindedness was a hindrance to attitude studies in this field. Existing scales by Ferguson (1942), Lentz (1946), Likert (1932), Manry (1927), Neumann (1927), and Stagner (1942) measure the dimension of nationalism-internationalism, rather than worldmindedness (in sampson \& Smith, 1957; in Shaw \& Wright, 1967).

International-mindedness refers to interest in or knowledge about international affairs. The concept of worldmindedness, in contrast, designates purely a value orientation apart from knowledge about or interest in international relations. The scale identifies as highly worldminded the individual who favors a world view of the problems of humanity, whose primary reference group is humankind rather than English, French, African, etc. Such a person may or may not have an interest in and knowledge about international affairs. As is observed in the political arena today, one may be internationally aware but not worldminded. Sampson and Smith credit Murphy's (1945) contribution at a symposium on education for world citizenship with their working definition of the concept of worldminded (Sampson \& Smith, 1957).

Research (Good, 1966; Cook, 1975; McCall, 1980) indicates that descriptive studies include present facts or current conditions concerning the nature of a group of 
persons and may involve the procedures of induction, analysis, classification, enumeration, or measurement. The purpose of descriptive-survey investigations may be:

1. to serve evidence concerning an existing situation or current condition.

2. to identify standards or norms with which to compare present conditions in order to plan the next step.

3. to determine how to make the next step (having determined where we are and where we wish to go) (Good, 1966, p. 192).

Research can reflect different purposes and therefore differing levels of comprehensiveness in the models used to guide the research process. One way to distinguish purposes calling for different degrees of comprehensiveness is to differentiate between basic and applied research (Cook, 1975). There is a difference between research for the purpose of testing out the validity of assumptions (research undertaking begins with one or more assumptions) and research for the purpose of enabling better immediate decision making or planning. The former defines basic research and the latter applied research. Benedict (1971) has clarified this distinction as being one between "conclusion-oriented research" and "decision-oriented research." The latter is considered more relevant for the purpose of educational evaluation (Cook, 1975) and is the purpose of this study. 
Decision-Oriented Research

Many important decisions in education can be made more wisely if descriptive data are available. When a researcher wishes to evaluate present conditions as a normative basis for making judgments or decisions, as in this study, the approach is usually a descriptive one.

Besides setting forth descriptive data about relevant situations, the researcher not only considers relationships among events or phenomena but also discerns how those factors are altered when related to other variables.

Labels for descriptive research abound. For the purpose of brevity, three types will be discussed here.

1. Survey research--aids in decision making or planning further research

2. Correlational research--primarily used for prediction by studying variables

3. Causal-comparative (or ex post facto) research-typically involves the analysis of characteristics associated with two different groups of subjects.

The second and third types of descriptive research will not be employed in this study for the following reasons. Characteristics which are observed to be closely related to one group but not the other are often presumed to have some sort of causal relationship to the factor on which the groups differ. But the causal-comparative research does not isolate the cause, and there could be an intervening factor related to the actual cause. Only experi- 
mental research can isolate the causal factor (Cook, 1975). In correlation research the coefficient indicates the nature and the extent of the relationship(s) involved. One danger in interpreting correlations is to assume that because two variables are related in predictable fashion to one another with a high degree of probability, they are also in a causal relationship. This is not necessarily the case. For one thing, there is never more than a probable relationship between variables in any case. It is quite possible for two variables to be related to one another with a high degree of probability but with a third variable accounting for the nature of the relationship (Cook, 1975). With the foregoing in mind, this study does not purport to nor warrant the application of this instrument for the purpose of conclusion drawing or diagnoses, but serves as a beginning for further research into what constitutes the environment and attitude formation of a world-minded individual.

\section{DESIGN}

The descriptive-survey design was selected: a) to secure evidence concerning an existing situation, that is, the worldmindedness attitudes of administrators in higher education in the state of Oregon; b) to identify norms in their backgrounds with which to compare present conditions to plan the next step; and c) to determine the 
direction and procedure of the next step.

Population

The research population was selected from each of

the following institutions of higher education in oregon:

\title{
Community Colleges
}

Chemeketa Community College

Clackamas Community College

Lane Community College

Linn-Benton Community College

Mt. Hood Community College

Portland Community College

Rogue Community College

\section{Private Colleges}

\author{
Lewis and Clark College \\ Linfield College \\ Pacific University \\ Reed College \\ University of Portland \\ Warner Pacific College \\ Willamette University \\ State Institutions \\ Eastern Oregon State College \\ Oregon Institute of Technology \\ Oregon State University \\ Portland State University \\ Southern Oregon State College \\ University of Oregon \\ Western Oregon State College
}

The institutions selected are post-secondary accredited in the state of Oregon. They were selected according to location within the state, size of student body (largest enrollment, if possible) and type of institution-i.e., community college, private college and state institution. 
The researcher believes that an important purpose of the study was to learn if there was any discernable difference between different types of post-secondary institutions. Review of the literature (Lambert, 1980; Owens, 1981; Gress, 1979 ; Levin \& Weingort, 1974) suggests that administrators must be in the forefront of educational change-that is, they should be in the position to begin implementing global education into an already existing educational system. Therefore, administrators that were most likely to be in a position of implementing and facilitating change were selected.

Each institution dictates its own administrative hierarchy with different specific titles for similar positions. After a thorough review of each institution's catalogues and through phone interviews to learn which specific titles designated administrative responsibilities, the researcher decided that the selection of three or four administrators from each institution, rather than random selection, would be most beneficial to the study. Some institutions did not have schools of business or education, some combined different departments into one area of arts and sciences, and others had definite divisions. In order to obtain information from each type of academia, it was necessary to select specific administrators, while trying to maintain equal numbers from the different institutions and divisions within them. Consequently, presidents, vicepresidents for academic affairs, provosts, deans of 
instruction, deans of students, academic deans, and chairs and directors of individual schools (social science, education, business, arts and sciences) were selected. The 70 administrators were asked to participate in the study through a mailed questionnaire and follow-up mailings. (See Appendix B.)

\section{Instrumentation}

Questionnaires constructed to establish criteria on specific objectives are an efficient means to gather data (Gay, 1981; Cook, 1975; Good, 1966; Orlich, 1978). A questionnaire was chosen because of its cooperative nature, i.e., respondents were able to reply to sensitive attitudinal questions in privacy and at their own leisure. Furthermore, the respondents were contacted at the same time, received identical questions, interviewer bias was avoided, distant administrators were made available and uniform data were gathered.

The data were obtained utilizing two instruments combined into one: a questionnaire composed of demographic, socio-economic, personal and educational background information, and the "World-mindedness Scale," developed by Donald I. Sampson, University of British Columbia, and Howard P. Smith, Bennington College, Vermont. The instrument was tested in a field test conducted in four institutions similar to the ones in the actual study, and the population was of similar status to the 
actual study. The institutions are in the state of oregon: Central Oregon Community College, Southwestern Oregon Community College, George Fox College, and Oregon Graduate Center. Slight modifications in the instrument were made before it was used in the actual survey.

When Sampson and Smith (1957) translated worldmindedness into an operational language of scores on an attitude scale, with worldmindedness at one end of the continuum and national-mindedness at the other end, it required the selection of items that were not statements of fact and that were not topical in reference. Sixty items that met requirements and that pertained to various aspects of the world-minded frame of reference were incorporated into a Likert-type scale. The scale was administered to 120 university students, and two criterion groups were selected from their scores--the highest $10 \%$ and the lowest 108 of the scores. The 60 items were scored on a six-point scale, and the mean extent to which each of them differentiated between the two criterion groups was determined. All items whose discriminative power was two scale points or more were retained. The scale was then reduced to a final form of 32 items.

The statements in the Worldmindedness scale were arranged so that every eighth item pertained to the same dimension in the following order throughout the scale: religion, immigration, government, economics, patriotism, 
race, education and war. There were 16 pro-worldmindedness items and 16 anti-worldmindedness items and each of the dimensions was represented four times. (See Table I.)

TABLE I

THE WORLDMINDEDNESS SCALE FORMAT OF PRO- AND ANTI-WORLDMINDEDNESS QUESTIONS

\begin{tabular}{|c|c|c|c|c|c|c|c|c|}
\hline & $\begin{array}{l}\text { reli- } \\
\text { gion }\end{array}$ & $\begin{array}{l}\text { immi- } \\
\text { gration }\end{array}$ & $\begin{array}{l}\text { govern- } \\
\text { ment }\end{array}$ & $\begin{array}{c}\text { eco- } \\
\text { nomics }\end{array}$ & $\begin{array}{l}\text { patri- } \\
\text { otism }\end{array}$ & race & $\begin{array}{l}\text { educa- } \\
\text { tion }\end{array}$ & war \\
\hline 1 & $2 I$ & 22 & 23 & p24 & p25 & 26 & 27 & 28 \\
\hline 2 & 29 & p30 & p31 & 32 & p33 & p34 & p35 & 36 \\
\hline 3 & 37 & p38 & 39 & $\mathrm{p} 40$ & 41 & 42 & $\mathrm{p} 43$ & p44 \\
\hline 4 & 45 & p46 & $\mathrm{p} 47$ & 48 & 49 & p50 & p51 & p52 \\
\hline
\end{tabular}

By checking one of the alternative responses on a six-point Likert scale, ranging from "strongly agree" to "strongly disagree," the respondents indicated the extent of their worldmindedness. The respective scores of 6 (strongly agree), 5 (agree), 4 (mildly agree), 2 (mildly disagree), 1 (disagree), 0 (strongly disagree) were given to pro-worldminded items, and the scores of $0,1,2,4,5$, and 6 were given to anti-worldminded items. Thus the possible range of scores on the scale was from 0 , for extreme national-mindedness, to 192 for extreme worldmindedness, with 96 as the theoretical neutral point. The respondents' scores for the worldmindedness attitude questions were divided at the mid-point and classified as neutral, worldminded or nationalistic. 
Sampson and Smith (1957) determined both by the oddeven and by the test-retest methods that the reliability of the full scale was acceptable for use in the measurement of individual attitudes, according to convention recognized by Krech and Crutchfield (1948). Based on an analysis of the responses of 56 college students, the product-moment correlation between the odd and even items was 0.87 , corrected to 0.93 by the spearman-Brown formula. A test-retest reliability check with 33 students over a 28-day interval yielded a product-moment correlation of 0.93 (Sampson \& Smith, 1957).

The internal consistency of the Worldmindedness Scale argues for its validity; a consistent frame of reference appeared to be operative through all the attitude areas represented in the scale in previous uses.

Empirical evidence of the scale's validity came from its use in research (Sampson \& Smith, 1957; Smith, 1955). Research use of the scale had yielded several types of empirical evidence of validity: (a) high correlation with another scale whose validity had been independently established and whose content was rather similar to that of the Worldmindedness Scale items; (b) the capacity to distinguish at a statistically significant level between the attitudes of subjects in groups known to differ in worldmindedness, and (c) the capacity to predict significant statistical differences between highly world-minded and 
highly national-minded subjects in certain types of internationally oriented behavior (Sampson \& Smith, 1957). The custom of establishing the validity of a psychological test or attitude scale by correlating it with another test or scale similar in content had little to recommend it unless the validity of the instrument with which the scale was correlated had been independently determined. With that knowledge in mind, Sampson and Smith (1957) selected an Il-item form of the Ethnocentrism Scale of the California Public Opinion Scale (Adorno, 1950) and determined its product-moment correlation with the Worldmindedness Scale, using a sample of 223 secondary school and college students. The Pearson coefficient was 0.71 , indicating a high negative association between worldmindedness and ethnocentrism. This figure contrasts with a correlation of -0.53 between the Worldmindedness Scale and a 10-item Political Economic Conservatism Scale from the California Study and a correlation of -0.29 between the Worldmindedness Scale and eight of the 15 items on the Democracy Scale, adapted by Riecken from the Ideology Test of the First Bethel Conference of the National Training Laboratory in Group Development (1953). These correlations indicated that worldmindedness is negatively associated with political and economic conservatism and with authoritarian attitudes and positively associated with belief in democratic group process (high belief in 
democratic group process receives a low score on the Democracy Scale). All coefficients were statistically significant beyond the 18 level of confidence (Sampson \& Smith, 1957).

Validity was also tested by "known group" technique. In a study of attitude changes among American students who went to Europe in the summer of 1950 (Smith, 1955) the mean of the Wordmindedness Scale of 1962 students was compared with the mean of 25 participants who went to Europe with the Quaker International Voluntary Service (QIVS). Among the qualities the QIVS considers most important for acceptance into its program is a worldminded frame of reference. The Worldmindedness scale mean of the QIVS participants, according to a pre-summer measurement, was 155.82, compared to a mean of 123.65 for the 192 other subjects. Another group tested exhibited a Worldmindedness Scale mean of 148.23 QIVS as compared to a mean of 125.78 for other subjects tested. The statistical difference was significant (Sampson \& Smith, 1957).

A comparison of the Worldmindedness Scale standard deviation of QIVS scores with the standard deviation for other subjects showed, as one would predict from knowing the selectivity of the QIVS sample, a much greater degree of homogeneity in worldminded attitudes for the QIVS subjects; a sample of 25 QIVS scores had a standard deviation of 16.86 , compared to a standard deviation of 
25.03 for 205 other subjects (Sampson \& Smith, 1957). Sampson and Smith (1957) found that worldmindedness is a relatively stable attitude as is indicated by correlations of 0.69 for a sample of 18 subjects and 0.75 for another sample of 12 subjects.

Idea development for appropriate questions by the researcher were extracted from the review of literature on the basis of which would elicit the most valid information regarding world-minded attitude formation.

In order to discover any personal characteristics associated with global awareness, a background questionnaire was developed for this study. Items were collected from previously conducted surveys and various Educational Testing Service instruments (Barrows, 1982; Pike, 1979; Hartshorne, 1981). The questions were examined and items selected that were appropriate to the study's purpose. Because socio-economic perspective appears to be a potentially significant factor, data were collected on administrators' ethnicity, country of birth, and family educational level (Lentz, 1946; Barrows, 1980). It was felt that educational experience, formal and informal, and college major and coursework would probably contribute to levels of worldmindedness (Barrows, 1980).

How administrators garnered information about world events was also expected to influence their development of global awareness (Pike, 1979). The research questions addressed were: 
1. In what ways do factors of age, sex, ethnic background, education, and socio-economic background relate to the attitudes as measured by the Worldmindedness Scale?

2. Does exposure to the following selected varaibles influence the administrator's view or perception of viewing the world as a whole?

- foreign language exposure

- travel (military, vacation, business)

- exchange programs (faculty or student)

- personal contacts with people of a different culture

- the effect of university coursework on global awareness

- media exposure (news via TV, radio, newspaper, magazine

\section{PROCEDURES}

The two instruments were combined into a single questionnaire and mailed with an accompanying cover letter to 70 administrators in the winter of 1983.

Sixty of the 70 subjects returned completed questionnaires. A response rate of $86 \%$ was achieved, using a followup procedure. In response to the initial mailing, 36 questionnaires were completed and returned. A follow-up postcard to nonrespondents was sent two weeks after the initial mailing, yielding an additional 13 questionnaires. A second letter (third follow-up) accompanied by another copy of the questionnaire was mailed one month after the original mailing. An additional 11 questionnaires were received. A fourth follow-up (a second postcard) was mailed one week later with no questionnaires returned. (See Table II.) 
TABLE II

THE NUMBER AND PERCENT OF COMPLETED QUESTIONNAIRES RETURNED IN

RESPONSE TO EACH MAILING

\begin{tabular}{lccc}
\hline Mailing & Date & $\mathrm{n}$ & Percent \\
\hline Initial letter & $2-14-83$ & 36 & 51 \\
First follow-up & $2-25-83$ & 13 & 19 \\
Second letter & $3-14-83$ & 11 & 16 \\
Fourth Follow-up & $4-04-83$ & 0 & 0 \\
No response & & $\underline{10}$ & 14 \\
\multicolumn{1}{c}{ TOTALs } & & 70 & 100 \\
\hline
\end{tabular}

DATA ANALYSIS

Data were computer analyzed by statistical programs found in the Statistical Package for the Social Sciencies (SPSS), (Kleska, Nie, \& Hull, 1975).

The first undertaking in the data analysis was to determine the pattern of the cases on each variable through the characteristics of mean, standard deviation and frequency counts.

After examining the distributional characteristics of each individual variable, investigation of the independent variables was performed using crosstabulation. This is the most commonly used method of analysis in the social sciences (Kleska, 1975). 
Often it is desirable to summarize the relationship depicted in a crosstabulation table with a measure of association or a test of statistical significance. A measure of association indicates how strongly two variables are interrelated.

The chi-square statistic was then used to determine the likelihood that the variables were statistically independent. The chi-square statistic is converted into a probability figure called the significance level. This researcher chose the .05 significance level indicating that if the same type of sample was drawn from the population an infinite number of times, 5 out of any 100 would have that strong or stronger a relationship. This indicates that the pattern was very unlikely to have occurred by chance.

Another type of analysis used in this study was the comparison of sample means. The statistical question answered was whether two means were significantly different or if the similarity was so close that there was a reasonable probability that the means did not differ in the larger population. This commonly used procedure is the t-test. 
CHAPTER IV

DATA PRESENTATION AND DISCUSSION

\section{INTRODUCTION}

Many prominent educators endorse an educational objective of worlamindedness (Burn, 1980a, 1980b; Pike, 1979; Torney-Purta, 1981). The worldmindedness person's reference group is humankind rather than different nationalities or ethnic groups. Worldmindedness is both cognitive and affective (Urso, 1981) providing certain abilities in that person. Kenworthy (1952) has stated that the desired characteristics of such a person must be more definite. However, little investigation has been done in this area, and it is with this knowledge in mind that this study was completed.

Two questionnaires were mailed to 70 administrators in higher education in the state of oregon to glean insights into factors that influence a person to develop a worldminded attitude. One questionnaire was a worldmindedness attitude questionnaire, developed by Sampson and Smith (1957). That questionnaire was accompanied by a demographic, socio-economic, personal interest and educational background questionnaire.

A descriptive narrative of the 60 administrators who 
responded to the questionnaire is presented first in this chapter, followed by a discussion of the interaction of the interdependent variables of family, personal, socioeconomic and educational backgrounds. These variables are then examined in conjunction with the attitude as measured by the worldmindedness scale. Last, the distinct subgroups of community college, private institutions, and state institutions are explored in relation to the variables and the worldmindedness score.

Demographic Characteristics

The majority of the 60 respondents (53 or $88.3 \%$ ) were Caucasian males, possessing a mean age of 49.8 years with an age range between 35 and 64 years. Five administrators ( $8.3 \%$ ) were of minority extraction, one being born outside North America. Seven females represent a total of $11.7 \%$. (See Table I in Appendix A.)

Compared to the latest educational statistics (Dearman, 1982), both minority and female administrators are underemployed in Oregon as compared to the rest of the United States. Female administrators are at the 16.48 level nationally, while only 11.78 in Oregon. Minority administrators in Oregon are $5.7 \%$ below the national average. Minority females are also below the national average (1.8\%) here in Oregon at .98\%. (See Table II in Appendix A.) 
FAMILY BACKGROUND CHARACTERISTICS

Educational

Respondents reported that $76.3 \%$ of their mothers finished high school or a higher educational level, while 66.18 of their fathers were also in that category. Only 11.7\% of the mothers had a bachelor's degree or more, while fathers ranked at the 16.78 level. (See Table III in Appendix A.)

These figures are consistent with the 1982 national findings as reported by Dearman (1982). The samples selected for the comparison were chosen to match the approximate ages of the respondents' parents' ages.

Foreign Language in the Home

Thirty-two (36.7\%) of all the administators came from a home where foreign language was spoken either occasionally, part-time or continuously. Considering the ages of the administrators and the respective ages of their parents, the probability is that there are several firstand second-generation Americans in the sample, accounting for the foreign language in the home.

Political Party

Administrators reported that $37(61.78)$ belong to the Democratic Party, while 14 (23.3\%) belong to the Republican Party. of the eight (13.3\%) who responded to the category "other," six wrote in "Independent." 


\section{Foreign Language Contact}

Before leaving high school, 40 respondents $(66.7 \%)$ reported that they were associated with a person who spoke a foreign language. Thirty percent (18) administrators had contact with foreign language speakers that were not in the home.

Respondents were asked what type of personal contact they have had with a foreign person that had influenced their attitudes. Forty-nine (81.78) administrators reported having had multiple contacts with family, student peers, work associates, teachers and social acquaintances. Only 3 (5.0\%) reported having had none at all.

\section{Experience Outside the United States}

An astounding $98.0 \%$ of the administrators had traveled outside the United States with 30 (63.38) in a combination of ways. The largest contingent was as tourists (78.3\%) followed by business travel (43.38), military (38.3\%), other (16.7\%), teaching (16.7\%), and student exchange (10.0\%). (See Table IV in Appendix A.)

Media and World News

World news acquisition by newspaper reading was reported by 88.48 of the administrators. Equally high was the number of subscribers to a news magazine that carries world news $(78.3 \%)$.

Seventy percent of respondents watch world news five or more times a week while only 108 claim not to watch at all. 


\section{EDUCATIONAL BACKGROUND CHARACTERISTICS}

Educational Level

The administrators' educational level was consistently high as would be expected with this population. (See Table III.)

TABLE III

ADMINISTRATORS' EDUCATIONAL LEVEL

\begin{tabular}{lcc}
\hline Educational Variable & $\mathrm{n}$ & $\frac{8}{8}$ \\
\hline Bachelor's Degree & 1 & 1.7 \\
Master's Degree & 12 & 20.0 \\
Doctorate & 47 & 78.3 \\
Total & 60 & 100.0 \\
\hline
\end{tabular}

Major Field of Study

It is interesting to note that there is a concentration of major study in the social sciences throughout the different degree levels--bachelor's degree, 33.3\%, master's degree, 31.7\%, and doctorate, 28.3\%. At the graduate level there is a decided increase in education majors, equalling social science majors (master's, 28.38 , and doctorate, 28.38). (See Table $V$ in Appendix A.) The highest degree earned by each administrator again finds the subject of social sciences and education in the lead. Eighteen (30.0\%) chose social science and 19 (31.7\%) education. (See Table IV.) 
TABLE IV DISTRIBUTION OF RESPONDENTS TO MAJOR FIELD
FOR HIGHEST DEGREE EARNED

\begin{tabular}{lrr}
\hline Major Field Variable & $\mathrm{n}$ & $\frac{8}{n}$ \\
\cline { 2 - 3 } Science & 7 & 11.7 \\
Social Science & 18 & 30.0 \\
Business & 3 & 5.0 \\
Education & 19 & 31.6 \\
Arts and Letters & 5 & 8.3 \\
Other & 2 & 3.3 \\
Combination* & 5 & 8.3 \\
Total & 59 & 100.0 \\
\hline
\end{tabular}

*Combination Majors:

Science and other

Social Science and Education

Social Science and Arts and Letters

Education and Arts and Letters

Education and Science

Foreign Language Study

Ninety percent of administrators had studied a foreign language, and $50 \%$ had studied foreign language three or more years. (See Table V.)

\section{TABLE V}

RESPONDENTS' FOREIGN LANGUAGE STUDY

\begin{tabular}{lccc}
\hline Length of study & $\mathrm{n}$ & $\frac{8}{8}$ \\
\cline { 2 - 3 } Less than 1 year & 12 & 20.0 \\
1 to 2 years & 12 & 20.0 \\
3 to 4 years & 20 & 33.3 \\
More than 4 years & 10 & 16.7 \\
Never & 6 & 10.0 \\
Total & 60 & 100.0 \\
\hline
\end{tabular}


Course Work

Respondents were asked if they believed any of the listed courses contributed to their awareness of world problems, issues, cultures or people.

Fifty-six (93.38) of the respondents said they believe that courses in the social sciences (history, geography, psychology, political science, sociology and anthropology) contributed to their awareness. The next closest rating was $31(51.7 \%)$ respondents, citing literature, English and journalism as helpful. Economics and business along with philosophy and religion equally obtained 26 (43.3\%) positive replies while modern language followed closely with $25(41.7 \%)$. (See Table VI in Appendix A.)

\section{PROFESSIONAL BACKGROUND CHARACTERISTICS}

\section{Institution}

The 60 respondents were equally divided between the three types of institutions. (See Table VI.)

TABLE VI

RESPONDENTS' INSTITUTION OF EMPLOYMENT

\begin{tabular}{lccc}
\hline Institution Variable & $\mathrm{n}$ & $\frac{8}{20}$ & \\
Community College & 19 & & 31.7 \\
Private 4-Year College & 20 & & 33.3 \\
State 4-Year College & $\frac{1}{60}$ & $\frac{1.7}{100.0}$ \\
Missing & & & \\
\hline
\end{tabular}


THE WORLDMINDEDNESS SCALE SCORES

Mean

The Worldmindedness Scale ranges from 0 for extremely nationalistic to 192 for extremely worldminded with 96 as the theoretical neutral. Previously tested scores for a highly worldminded group of individuals, QIVS (p.73), had a mean of 155.82. Another group tested, American students returning from a European summer study program, had a mean of $123.68(p .73)$.

The Oregon administrators in this study scored a mean of 120.08 with a standard deviation of 21.69. The scores ranged between 71 and 180. (See Table 7 in Appendix A.) Forty-one respondents (68.38) scored within one deviation of the mean, i.e., above 98.39 and below 141.78. Eight scores (13.3ㅇ) were in the low range and 9 (15.0) in the high range. (see Table VII.)

\section{TABIE VII}

RESPONDENTS' WORLDMINDED SCORE REDUCED TO A TRICHOTMOUS SCALE

\begin{tabular}{|c|c|c|c|}
\hline Worldminded Scale & $\mathrm{n}$ & 8 & Cum. 8 \\
\hline Low & 8 & 13.3 & 13.8 \\
\hline Mid & 41 & 68.3 & 84.5 \\
\hline High & 9 & 15.0 & 99.5 \\
\hline Missing & 2 & 3.3 & \\
\hline Total & 60 & 100.0 & 100.0 \\
\hline
\end{tabular}


The Eight Sub-Dimensions

When the scale was divided into the eight dimensions of religion, immigration, government, economics, patriotism, race, education and war, a score was calculated as the arithmetic mean of valid responses to worldmindedness within a continuous range of 0 - 6 with 6 representing worldmindedness. The following means were determined for each dimension. (See Table VIII.)

TABLE VIII

ARITHMETIC MEANS RANGING FROM 0 TO 6

OF THE EIGHT DIMENSIONS OF THE WORLDMINDEDNESS SCALE

\begin{tabular}{lr}
\hline \multicolumn{1}{c}{ Nationalistic } & Worldmindedness \\
Dimension Variable & $\underline{\text { Mean }}$ \\
\hline Religion & 5.21 \\
Race & 4.90 \\
Patriotism & 3.69 \\
War & 3.60 \\
Education & 3.60 \\
Immigration & 3.31 \\
Economics & 3.09 \\
Government & 3.08 \\
\hline
\end{tabular}

Each dimension was studied for an imbalance in responses. Five questions (numbers 26, 27, 29, 37 and 42) stood out with a dichotomous or trichotomous response. These questions all dealt with race and religion. The rest of the questions had a wide range of responses. 
Interaction Between Independent Variables

How do these results of background variables relate to each other? As will become apparent, concurrences with the Educational Testing Service (ETS) study (p. 44 ) and the "Other Peoples, Other Nations" study (p.43) were found. Due to the lack of significant numbers of highly nationalistic or world-minded respondents, statistical analysis was difficult to compute. Sixty-eight and three-tenths percent $(68.3 \%)$ were within one deviation of the mean.

\section{Family Characteristics}

Among family background variables, there appears to be an association between low levels of education for the father--and separately for the mother--and limited or no study abroad. The association with the father's educational level was $x^{2}=25.30, p=.0048$; with the mother's educational level it was $x^{2}=11.61, p=.0204$. This result may be due to only 6 of 59 respondents having studied outside the United States.

This finding may be related to the conclusions of Lentz (1946), Barrows (1980) and Pike (1979) that parent educational level affects attitudes and knowledge, that desire to spend longer periods abroad for the purpose of enhancing knowledge and attitudes could be affected.

There was a statistically significant $\left(x^{2}=13.74\right.$, $p=.0326$ ) association found between shorter length of 
study abroad and more foreign language in the home. There was no statistically significant finding between foreign language in the home and vacation travel.

\section{Personal Characteristics}

A weak statistical significance $\left(\chi^{2}=10.33, \mathrm{p}=\right.$ .0663) was found between multiple contact with foreign people who influence them and vacation travel. Forty-one (83.7\%) who vacationed outside the United States had had multiple contacts.

Six of the nine administrators who taught abroad (66.7\%) had multiple contacts that influenced them (statistical significance of $\left.x^{2}=10.53, p=.0614\right)$. It is not known if these contacts (family, peer group, work associates, social acquaintances) were before, after or during the outside experience. A statistically significant finding (.0396) was found between teaching duration and multiple contacts. Again, when the contacts were is not known.

A statistical significance of $\chi^{2}=13.11, p=.0223$ was found between newspaper reading and multiple contacts. A strong association (statistical significance of $\chi^{2}=6.40$, $\mathrm{p}=.0114$ was found between newspaper reading and studying a foreign language.

The literature suggested that a world-minded person is informed about the world, that with personal experience comes a heightened, continuing interest in world events (Edgerton, 1976). 
Applying the same theory, foreign language learning could also lead to increased interest in world news.

Pike (1979) observed that the students in the "Other Nations, Other People" study clearly perceived television and reading as having strong influence on their thinking. Male teachers in the same study also rated reading as an important variable in attitude formation.

The ETS study found that the respondents with the highest scores reported regular reading of world news.

A major conclusion of the ETS study was the correlation between the way students acquire information, their knowledge and attitudes toward global awareness. Newspaper reading is closely associated with a positive world-minded attitude.

A statistically significant association $\left(x^{2}=29.80\right.$, $p=.0002$ ) was also found between increased television viewing and higher educational levels. Although no statistically significant association was found, radio listening increased with the level of academic degree attained.

There was no statistically significant findings between the political party and parents' educational level, respondents' educational level or background experiences.

Educational Characteristics

No statistically significant associations were found between parents' level of education and the level attained by respondents or between parents' level of education and 
whether the administrators came from a home where a foreign language was or was not spoken.

A finding approaching statistically significant at the .05 level was found between the level of education achieved and business travel $\left(x^{2}=5.38, p=.0678\right)$. Even though the finding was not highly statistically significant, it was noted that the higher the educational level the more likely the outside experience from vacation travel existed. (See Table IX.)

TABLE IX

RESPONDENTS' EDUCATIONAL LEVEL AND VACATION LEVEL

\begin{tabular}{|c|c|c|}
\hline Vacation Variable & $\mathrm{n}$ & 8 \\
\hline $\begin{array}{l}\text { No } \\
\text { Master's } \\
\text { Doctorate }\end{array}$ & $\begin{array}{l}5 \\
8\end{array}$ & $\begin{array}{r}8.3 \\
13.3\end{array}$ \\
\hline $\begin{array}{l}\text { Yes } \\
\text { Bachelor's } \\
\text { Master's } \\
\text { Doctorate }\end{array}$ & $\begin{array}{r}1 \\
7 \\
39\end{array}$ & $\begin{array}{r}1.7 \\
11.7 \\
65.0\end{array}$ \\
\hline TOTAL & 60 & 100.0 \\
\hline
\end{tabular}

A slight association $\left(x^{2}=13.43, p=.0621\right)$ was seen between major and foreign language in the home. Fourteen education majors $(73.7 \%)$ came from homes where no foreign language was spoken, whereas 12 social science majors (66.78) came from homes where foreign language was spoken, an indication that the foreign language helped to 
create an interest in the social sciences.

As would be expected, a statistically significant association was found between study abroad and length of foreign language study $\left(x^{2}=6.666, p=.0357\right)$. Of the 30 administrators who have studied foreign languages three or more years, $12(75.08)$ earned their highest degree in the social sciences. Six (40.98) studied education. (See Table VIII in Appendix A.)

Independent Variables with High, Mid and Low Range Worldmindedness Scores

Cross-tabulations were conducted on the high, mid, and low scores with the independent variables to ascertain any differences and/or associations between them. The nine high scores and eight low scores were examined to learn if there were any outstanding characteristics of the two extremes.

A noticeable difference was found in the age grouping of high and low scoring respondents. Six of the 9 high scorers (77.8\%) were 44 years or younger, while 2 of 8 low scorers (25.0\%) were 43 or younger. (See Table X.) of the 9 high scorers, 3 were female, and all were Caucasian. One female and 2 males of minority extraction were in the low scoring group.

\section{Family Variables}

It was noted that 38 mothers $(66.68)$ and 31 fathers (54.48) that had some college, a bachelor's or graduate degree, produced an offspring in the mid to high score 
TABLE $X$

\section{RESPONDENTS' AGES AND HIGH AND \\ LOW WORLDMINDEDNESS SCORES}

\begin{tabular}{|c|c|c|c|c|}
\hline \multirow[t]{2}{*}{ Ages } & \multicolumn{2}{|c|}{ High } & \multicolumn{2}{|c|}{ Low } \\
\hline & $n$ & $q$ & $\mathrm{n}$ & q \\
\hline $30^{\prime} \mathrm{s}$ & 2 & 22.2 & 0 & 0.0 \\
\hline $40^{\prime} \mathrm{s}$ & 4 & 44.5 & 2 & 25.0 \\
\hline $50^{\prime} \mathrm{s}$ & 1 & 11.1 & 3 & 37.5 \\
\hline $60^{\prime} \mathrm{s}$ & 2 & 22.2 & 3 & 37.5 \\
\hline TOTAL & 9 & 100.0 & 8 & 100.0 \\
\hline
\end{tabular}

range. Mothers' educational level was lower with the low group while fathers' was equal in both groups.

Thirty-seven and five-tenths percent (37.5\%) of the low score group spoke a foreign language in the home.

Personal Characteristics

In the mid to high range, 56.28 of the respondents said they were Democrats and $17.6 \%$ were Republicans, while $12.3 \%$ were "Other." The low level scorers were three Democrats, four Republicans and one other.

There is a noticeable difference in political party affiliation between high and low scorers. Democrats outnumbered Republicans and others combined in high scorers, while the reverse is true for low scorers. (See Table XI.)

The ETS study found a high correlation between students' liberal political orientation and pro-human rights, anti-war, pro-world government orientation. Lentz 
TABLE XI

RESPONDENTS' POLITICAL PARTY AND HIGH

AND LOW WORLDMINDEDNESS SCORES

\begin{tabular}{|c|c|c|c|c|}
\hline \multirow[t]{2}{*}{ Party Variable } & \multicolumn{2}{|c|}{ High } & \multicolumn{2}{|c|}{ Low } \\
\hline & $\mathrm{n}$ & $z$ & $\mathrm{n}$ & 安 \\
\hline Democratic & 5 & 55.6 & 3 & 37.5 \\
\hline Republican & 1 & 11.1 & 4 & 50.0 \\
\hline Independent & 3 & 33.3 & 1 & 12.5 \\
\hline TOTAI & 9 & 100.0 & 8 & 100.0 \\
\hline
\end{tabular}

(1946 and Allport (1954) also reported similar findings.

\section{Contact}

A look at the worldmindedness scores and exposure with foreign speaking people before leaving the United States reveals that 56.98 in the mid to high range responded affirmatively.

A higher level of multiple contacts was reported by the low groups $(87.58)$, then $(66.78)$ for the high group. When the total variety of contacts was compiled, the distribution was similar between family, student peers, work associates, teachers and social acquaintances with only a difference of 2 "more" in the high score group and one missing response in the high score group. This may be a further indication of the finding that it is not just contact but quality of contact (Kelman, 1970). Respondents who have been outside the United States 
had mid-range scores. The outside duration of stay ranged from never (0) to more than 2 years (128). Group I falls between range 1-5 and Group II between 6-12. (See Table IX in Appendix A.)

Much has been written about personal contact with foreign people to bring about mutual understanding. The high number $(85.7 \%)$ of mid to high scorers among the respondents and the concurring high percentage (98.0\%) of experience outside the United States would seem to support this expectation.

Smith (1955) noted that what a person's general attitude will be after an experience in another country will be determined by what the attitude is before leaving. Hensley and Sell (1979) stated that the extent of contact is an important factor, and Kelman (1970) stated that it was the status level as perceived by the host country as well as the sojourner that determined the attitudinal outcome.

These three different theories can be applied interchangeably to the findings in the study, depending on what is sought.

Only one (11.1\%) of the high group had military experience and that was for more than one year. Half of the low scorers had military experience, $50 \%$ spending less than one year and the other $50 z$ more than one year outside the United States. Both groups had equal numbers go on 
business trips for less than one year. Also equal were vacation travel times.

One student exchange was reported for less than one year in the high group with none in the low group. Two in the high group reported teaching outside the United states while none from the low group did.

The category "Other" for travel outside the United States drew $37.5 \%$ of the low group while only one (11.1\%) in the high group.

Military experience could either be attitudinally positive (in peacetime, with officer status and an opportunity to travel and meet natives, and having chosen to participate in the military) or negative attitudinal (wartime, no desire to go abroad as an unwanted force-e.g. Vietnam--and no time to meet natives). Business travel could also fit into the three theories. The feeling of excitement at the prospect of meeting new people and being respected as a business person from America or as a capitalist that "has to" go abroad.

Again, vacation travel is usually self-motivated, although a family member or friend could persuade a person to go. Depending on location of outside experience (Teheran versus Frankfurt), status could be extremely different and consequently a negative attitude could be strongly supported or a positive attitude could be enhanced. Length of stay has a tremendous impact on a tourist's attitude regarding 
new cultures and customs. There are three stages to "culture shock." First, everything is so different it is exciting. Second, everything is so different it is bad. And, third, everything is different but some is good and some is just different, not bad, but different.

Teacher and students have an opportunity to go through the culture shock stages and some tourists as well as military people will, too. Time is on the side of a positive attitude acquisition in a new environment. Mortenson (1976) supports this theory. Respondents who studied outside the United States had a worldmindedness score mean of 126.66 versus 119.32 for those who did not $(t=-1.59, p=.130)$. Also, teaching outside produced a group mean of 125.88 on the scale, while no teaching abroad produced a mean of 119.02 , but no statistical significance was found ( $t=-0.87, p=0.387)$.

$\underline{\text { Media }}$

The world-minded person is, in general, informed about the world. One hundred percent of the high scorers read world news, while $75.0 \%$ of the low scorers did. Magazines that carry world news were subscribed to equally.

A t-test revealed a statistically significant finding $(t=-2.93, p=.007)$ that the group who acquired world news by newspaper reading had a mean worldmindedness score of 122.21, while nonreaders had a mean score of 108.47 . The eight low scorers (1008) watch world news on 
television three or more times per week, while only 77.88 of the high scorers watch that often. The literature suggests that those with worldmindedness attitudes are more active in seeking world news; locating articles to read is not considered as passive as watching television. There is a considerable difference between high and low scores and world news listening on the radio--highs (77.8\%) and lows $(12.58)$.

\section{Educational Characteristics}

Forty-nine respondents with graduate degrees (84.5\%)

were in the mid to high score range. (See Table XII.) High scores increased with degree level.

TABLE XII

RESPONDENTS' WORLDMINDEDNESS SCORE AND HIGHEST DEGREE EARNED

\begin{tabular}{|c|c|c|c|c|c|c|c|}
\hline \multirow{2}{*}{$\begin{array}{l}\text { Worldmindedness } \\
\text { Score } \\
\end{array}$} & \multicolumn{2}{|c|}{ Bachelor's } & \multicolumn{2}{|c|}{ Master's } & \multicolumn{2}{|c|}{ Doctorate } & rotal \\
\hline & $\mathrm{n}$ & 8 & $n$ & 8 & $\mathrm{n}$ & 8 & $\mathrm{n}$ \\
\hline Low & 0 & 0 & 1 & 1.7 & 7 & 12.1 & 8 \\
\hline Mid & 1 & 1.7 & 9 & 15.5 & 31 & 53.4 & 41 \\
\hline High & 0 & 0 & 2 & 3.4 & 7 & 12.1 & 9 \\
\hline TOTAL & 3 & 1.7 & 12 & 20.6 & 45 & 77.6 & 58 \\
\hline
\end{tabular}

Major field of study at both the master's and doctorate level of low scorers was more diverse than the high scorers' majors. When all the majors (for bachelor's, master's and doctorate degrees) from each respondent are 
combined into a total of majors studied, an interesting picture is presented. (See Table $\mathrm{X}$ in Appendix A.) The literature speaks of the need to study the social sciences and humanities to help form worldmindedness attitudes (Barrow, 1980; Burn, 1980; Pike, 1979; Queener, 1949). Many of the respondents in this study have studied in the social sciences and humanities and there is a large percentage of mid to high range scores. Consequently, one could suspect that from these data there is a connection. The difficulty arises when it is realized that low scorers have also studied social sciences.

\section{Foreign Languages}

The mid to high range scores revealed that 62.08 of the respondents studied a foreign language from one to more than four years. Of these, $25.8 \%$ studied three or more years. The high scoring respondents (88.9\%) studied foreign languages for one or more years and 50.08 of the low scoring group studied the same period of time.

A t-test revealed that non-foreign language learners had a worldmindedness score mean of 109.78 while foreign language learners scored a mean of 121.27 , although no statistical significance was found. $(t=-1.23, p=0.222)$

Barrows (1982) noted that affect is moderately associated with language proficiency. Whether it is causal or contributory is not known. 
Woridmindedness and Institution of Employment

An interesting aspect of this study was to see if there were any clear delineators between the three types of institutions: community colleges, four-year private colleges and four-year state colleges and universities. The total worldmindedness score was analyzed with each institution, family, personal and educational background, as well as with the eight subdimensions of the scale. Some statistically significant findings were noted and other particular associations are worthy of comment.

College administrators in higher education in the state of oregon vary little among the three types of institutions. To begin with, the grand scale scores showed community colleges to have 29.88 of the score in the mid to high range while four-year private and four-year state colleges and universities were both 28.18 with combined mid to high scores. (See Table XIII.)

TABLE XIII

RESPONDENTS' WORLDMINDEDNESS SCORES AND INSTITUTION OF EMPLOYMENT

\begin{tabular}{|c|c|c|c|c|}
\hline $\begin{array}{l}\text { Low, Mid, } \\
\text { Score Varia }\end{array}$ & $\begin{array}{l}\text { Colle } \\
\text { cc }\end{array}$ & Private & 4-Year & Total \\
\hline Low & 3 & 1 & 4 & 8 \\
\hline 8 & 5.3 & 1.8 & 7.0 & 14.0 \\
\hline Medium & 17 & 12 & 12 & 41 \\
\hline 8 & 29.8 & 21.1 & 21.1 & 71.9 \\
\hline High & 0 & 4 & 4 & 8 \\
\hline \multirow[t]{2}{*}{8} & 0 & 7.0 & 7.0 & 14.0 \\
\hline & 20 & 17 & 20 & 57 \\
\hline Total & 35.1 & 29.8 & 35.1 & 100.08 \\
\hline
\end{tabular}


The age of administrators at all three institutions was comparable.

The seven female administrators were placed as follows: three each at the community college and state schools, and one at the private school.

\section{Family Characteristics}

Half of the fathers of the community college group had less than a high school education, while only $35.3 \%$ of the private school administrators and 21.18 of the state institution group did.

There was a slight association between community college administrators' mothers' level of education and the administrators' worldmindedness scores. The higher the level of mothers' education the higher the worldmindedness score.

More private institution administrators' mothers had bachelor's degrees (17.6\%) than did community college administrators' mothers $(10.0 \%)$ and state institution administrators' mothers (5.38).

Foreign language in the home and exposure to people of foreign cultures showed no statistical significance of association, although foreign language in the home was experienced by $55.0 \%$ of the state respondents, $30.0 \%$ of the community college respondents, and 17.68 of the private institution respondents. 
Personal

College and political party affiliation were most evenly spread at the state four-year institutions. Private colleges registered only two parties, Democratic and Republican, while community college respondents affiliated mostly with the Democratic Party. (See Table XI in Appendix A.)

\section{Travel}

Two administrators at community colleges, three at the private institutions and four at the state institutions had taught outside the United States. Three community college administrators had been students abroad, as were three from the private institutions and none from the state schools. (See Table XIV.)

TABLE XIV

RESPONDENTS' OUTSIDE THE UNITED STATES

STUDENT AND TEACHING EXPERIENCE

DURATION AND INSTITUTION

OF EMPLOYMENT

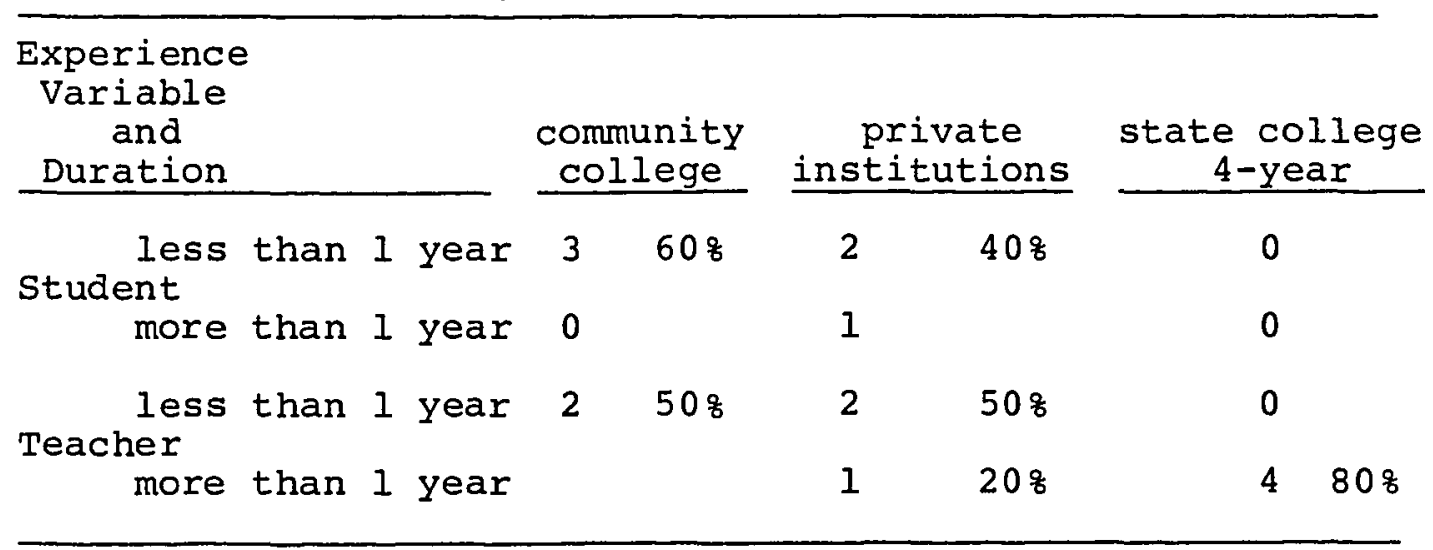


There was a statistical significance of $x^{2}=10.94$, $\mathrm{p}=.0272$ between the length of military serve and the institution of employment. Sixty-nine percent (69\%) that served the longest were employed in state schools. Out of the 26 respondents who had business experience, 26.98 were at the community colleges, 34.68 private institutions and 38.58 at state schools. Vacation travel was equally divided.

The educational level of administrators at the three kinds of institutions was similar. An equal number of administrators at four-year state and private schools had doctorates- $-85.0 \%$ and 88.28 respectively--while $65.0 \%$ at the community college.

Again, the majors of the highest degree earned and levels of worldmindedness demonstrated that a similarity between the different institutions exists. (See Table XII in Appendix A.)

\section{Foreign Language}

As stated earlier, $90.0 \%$ of all administrators surveyed had studied a foreign language, and all administrators in the state and private schools had studied a foreign language. A statistical significance $\left(x^{2}=13.02\right.$, $\mathrm{p}=.0015$ ) was found to exist between length of language study and employment at state and private institutions. (See Table XIII in Appendix A.) 


\section{CHAPTER V}

SUMMARY, CONCLUSIONS AND RECOMMENDATIONS

Sixty administrators in higher education in the state of Oregon were studied to ascertain if their family, personal and educational backgrounds had any affect on their worldmindedness. For this investigation, worldmindedness was defined as a value orientation toward the human race rather than knowledge or interest in international relations. The administrators were employed at community colleges, private or state colleges or universities. Respondents' positions in the administrative hierarchy ranged from president to directors or deans of academic departments.

Two separate instruments were combined into one questionnaire consisting of demographic, family, personal, educational and attitudinal information.

The research questions addressed were:

1. To investigate the relationships existing among and between family, personal and educational background variables

2. To investigate the relationships of family, personal and educational background variables to attitudes measured by the scale

3. To investigate the relationships between institutions of employment and attitudes measured by the scale. 
These questions and recommendations for future research on assessing the formative environment of a worldminded individual will be addressed in this chapter. How do administrators feel about worldmindedness? How well prepared are they to bring a global perspective to their respective institutions? Are there any particular backgrounds compatible with worldmindedness? What limitations were recognized that could be remedied in this investigation and how can the development of worldmindedness be encouraged in administration in higher education?

\section{Worldmindedness Among Oregon Administrators}

To help present a clearer picture of the attitudes expressed toward worldmindedness in this study, a brief comparison will be made with studies already cited.

The mean of the Oregon respondents was 120.08 (96

neutral and 192 extreme worldminded) as compared with a mean of 155.82 for the Quaker International group (p.73) and 123.68 for students returning from study abroad (p.73.) Only 10.38 were below the neutral 96 score, 39.78 were above the mean indicating mildly worldminded, and $31.0 \%$ were in the top third of the Worldmindedness Scale indicating worldmindedness.

In general, the Worldmindedness Scale scores (87.98) are above the theoretical neutral. Looking at the overall background variables of the general group there is a tendency to coincide with the literature findings and, more 
specifically, when addressing only the high and low scores. To summarize, parents' educational level, as noted earlier, was similar to that of the rest of the nation, but it is worthy of comment that $66.6 \%$ of mothers and $54.4 \%$ of fathers who attended college and higher levels of schooling produced offspring in the mid to high range. This would be in keeping with the findings of Pike (1979), Lentz (1946) and Barrows (1980) that parents' educational level does help to provide an environment conducive to worldmindedness. Contact with people of different cultures and languages is also conducive to worldmindedness. In fact, a large percentage of the respondents have been in contact with foreign persons. What is puzzling is that a larger percentage of low scorers reported having had influential contacts with foreign people.

Within the context of this study it is not possible to know the quality or duration of each type of influential contact. Nor is it possible to know what the pre-attitudinal position was before the contact. It may be noted that half of the low scorers did have military experience. Considering the age group of the low scorers 175.08 were 50 and older), it is likely that a wartime experience occurred--usually not considered a positive experience. Conversely, only one respondent in the high range group had military experience. Six of the 9 respondents with high scores were under 44 years, while only 2 of the low 8 were 
younger than 43. Could this indicate youths' concern for worldmindedness or political-sociological learning process experienced by this cohort group?

The fact that $98.0 \%$ of respondents with mid and high scores have traveled to foreign countries bears out findings in the literature (Flack, 1976; Kelman, 1962; Klineberg, 1954; \& Newcomb, 1976). The high percentage that had contact with foreign languages $(66.7 \%)$ before leaving high school and contact with different cultures (81.7\%) also supported findings in the literature. One student and two teacher exchanges were reported in the high scores and none in the low scores, further strengthening the argument that exposure is a prime factor in worldmindedness development.

The literature suggests that those with a more liberal orientation would be more likely to be world-minded (Lentz, 1946; Allport, 1954). Democrats, generally considered to be liberals, outweigh the Republicans and "Others" by 2 to 1 in the high score group but are in the reverse position in the low score group. Once again this agrees with findings in the literature.

World news gathering by newspaper reading showed a strong correlation with worldmindedness, not only in this study but was found to be a predictive measure for worldmindedness of persons in other countries (Torney-Purta, 1982). The majority of respondents read world news, while 1008 of the high scorers said they do. Television viewing 
was high across all score levels. Radio news listening was moderate, but again the general interest was exhibited to validate the literature's contention that motivation to know about the world is an indicator of worldmindedness.

\section{Education Summary}

The literature stipulates that it is necessary or beneficial to study social sciences (especially history) and humanities to score highly in world-minded attitudes (Barrows, 1981; Burn, 1980; Pike, 1979; \& Queener, 1949). Many of the educators have indeed studied in these areas, as well as in education. The high scoring respondents have, in fact, taken at least one of their graduate degrees in the social sciences where only one had in the low scores. In general, the higher scoring respondents had concentrated in the majors where high worldmindedness scores are expected. (See Table V, Appendix A.)

Survey data showed that 31.78 of the administrators earned their highest degrees in education, while $28.3 \%$ majored in education for their master's degree and 13.38 for their bachelor's degree. According to the ETs survey findings the Oregon respondent should place in the lower scoring group. Torney-Purta (1982) further analyzed this finding and did a series of regression analyses which allow the partialling out of some variables influenced in order to 
determine the influence of other variables. A selected sample was chosen from only those seniors who had reported their SAT or ACT scores. Groups were formed according to their majors. The importance of each major as a predictor of the score on the global awareness test was ascertained holaing constant (or partialling out) the effects of SAT or ACT scores, sex, exposures to various types of news media, courses taken and travel abroad. Education majors improved from ranking seventh out of seven to sixth out of seven. SAT/ACT is the strongest predictor. Sex is the second strongest predictor. Males in general did better on the global awareness than did females, but it is also the case that more females than males major in education. If students in education were equal in ability (as measured by SAT/ACT) equal in course work, equal in exposure to international news, and so on, students with majors in social sciences and history would still not demonstrate as high a level of global awareness. If students in education were equal in all these factors to majors in other fields, such as the humanities and engineering, they would be only slightly below them in global awareness.

As demonstrated by the ETS survey analysis, engineering and mathematics majors are involved with academic programs that have little to do with the content of the knowledge test. Yet these students scored almost as high on the test as the history majors. The test's emphasis 
on intellectual ability and the consistent finding that the more able students were generally the higher scorers may have been a contributing factor. This same theory could account for the education major respondents scoring from mid to high range on the scale. Even though education was the major, intelligence level for obtaining a doctorate would be higher than the general population, i.e., higher score attainment. Majors of respondents in the study were widely distributed but revealed heavy concentrations in the social sciences, foreign languages study and course work in the areas of history, geography, anthropology and other social science subjects. This finding again substantiates the literature in regard to awareness through course work. Respondents' scores strongly support the literature findings on relevant course work for a worldmindedness frame of reference. It is interesting that 93.38 believed that the social sciences they studied contributea to their awareness. Such opinion concurs with the Task Force Statement (1981) that a deeper knowledge and understanding of another culture can be gained through study of its history, geography, philosophy, language, politics and economics and that it is recommended that these subjects be emphasized in higher education to encourage the development of worldmindedness in students.

Earrows (1980) reported that course work taken in fields related to the content of the ETS test seemed to 
make no difference, but Torney-Purta (1982) reported that a regression analysis showed that seniors who had taken more history or geography achieved high scores even if they had not majored in these subjects. She reported further that majoring in history of social science makes a significant difference even when the number of courses is partialled out. These findings suggest that requirements regarding history and geography may be one way to encourage global awareness and worldmindedness.

Foreign language study was an important part of administrators' course work. Respondents with graduate degrees in social sciences had the second greatest number of foreign language study, but placed first in terms of the longest duration of foreign language study. While the correlation between graduate social science study and foreign language interest is not surprising, it is surprising that the group with the greatest number of persons studying foreign languages was education majors. A pattern developed that showed education majors at the highest degree level were consistently education majors from bachelor's degrees through doctorates, whereas social science majors had zero representation on the bachelor's degree level. One could conjecture that the social science majors at the highest level of education were the most motivated. (See Table VIII, Appendix A.) The $t$-test finding was most telling $(t=-2.19, p=.051)$. 
The non-language mean on the Worldmindedness scale was 109.78, and the language learners mean was 121.27, revealing that a considerable difference is made through language study.

This finding is also verified through the ETS study that found associations between knowledge and attitude and language and attitude, although there is no relationship between language and knowledge.

Forty-one and seven-tenths ( $41.7 \%)$ percent felt that foreign language acquisition benefited their development of global awareness. Torney-Purta (1982) found through regression analysis that attitudes of concern and empathy for those in other countries can be predicted by the number of foreign language courses taken. This may indicate that foreign language courses do have a role to play in fostering worldmindedness and stimulating an awareness in metalinguistics.

\section{Professional Summary}

In many respects, the institution employing the administrator had no correlation with the administrator's worldmindedness score. Age and sex of respondents were similar at all institutions. Fewer doctorate degrees were held at the community colleges $(65.0)$ versus private colleges (88.2) and state schools (85.0). Majors studied by respondents were comparable. The incidence of foreign language study and duration of study was greater at the four-year 
institutions. This fact, coupled with the knowledge that fewer doctorates are held by administrators at community colleges, could be responsible for the lack of high worldmindedness scores at those institutions. Worldmindedness scores were fairly evenly distributed, except for lack of high scores at the community colleges, but this was equalized with a greater proportion of mid-range scores than at either the private or state institutions.

The question arises that if most of the respondents have been exposed to people of foreign tongues, travel, appropriate course work and demonstrated interest in world news acquisition, wherein lies the reason for not having found more statistically significant associations?

As this study progressed, certain limitations presented themselves. The unusually high education level of all the administrators, the fact that most have traveled abroad, studied foreign languages, had multiple foreign contracts, read world news, and work in the world of education were common factors. How does one look for significant findings when the similarities of respondents are so overwhelming?

To complicate the issue further there were only eight low and nine high scores. One of the high scoring respondents removed the coding for institution of employment from the questionnaire and thus had to be removed from analysis procedures. 
These comments on analysis bring this researcher to the point of questioning the validity and the relevance of statistical significant findings in attitudinal or educational studies.

\section{Relevance of Statistical Significance}

\section{in Educational Research}

In recent years the use of statistical methods in educational research has increasingly come under attack (Baken, 1966; Carver, 1978; Clark, 1963; Cronbach, 1975; Morrison \& Henkel, 1970). These critics have recommended returning to the scientific method of data examination and replication rather than relying on statistical significance testing to provide equivalent information.

Instead of the decisive "accept" or "reject" statements that come from statistical significance testing, researchers need to look to empirical data, such as descriptive statistics that allow them to decide what kind of evidence exists in the data for the research questions or hypotheses: strong support, support, weak support, no support or disconfirming evidence (Carver, 1978). Statistical significance normally depends upon how large the research sample is. The more subjects, the more likely the researcher will find statistically significant results. Nunnally (1960) stated "if the null hypothesis is not rejected, it is usually because $\mathrm{N}$ is too small" (p. 643). Hays (1963) concurs when he states: 
"virtually any study can be made to show significant results if one uses enough subjects regardless of how nonsensical the content may be" (p. 326).

Because statistical significance in research depends on sample size, trivial results are often interpreted as significant (Carver, 1978). Conversely, statistically nonsignificant results are conventionally interpreted as providing no support for the research hypothesis even when the actual results support it, as I believe is the case with this study. When a small sample is used, large differences in the results can more often occur by chance and, therefore, provide no statistically significant evidence in support of the research hypothesis.

Rozeboom (1960) has pointed out that evidence in accordance with a research hypothesis should increase the researcher's belief in the hypothesis, whether the evidence is statistically significant or not.

Morrison and Henkel (1970) have summarized the controversy surrounding statistical significance tests as follows :

What we do without the tests then, has always in some measure been done in behavioral science and needs only to be done more and better: the application of imagination, commonsense, informed judgment, and the appropriate remaining research methods to achieve the scope, form, process, and purpose of scientific inference. (p. 3II)

My contention is that the Worldmindedness Scale scores are strong $(318$ in the top third in scale of 0 - 196) because as a whole the group did in fact participate 
in the important area variables as recommended by the existing literature.

Another alternative reason that more statistically significant findings were not found may be due to the instrument itself. Possibly, the Worldmindedness Scale by Sampson and Smith (1957) needs to be revamped, wordage made more relevant to post-Vietnam and/or future nuclear catastrophe. The types of questions found on the Worldmindedness scale may also be too difficult to answer even though the Likert Scale did provide a six-point scale response. Possibly an open-ended response section should be considered.

Another change in the instrument could be in word usage, such as instead of using the word "influence," use adjectives like negative, positive or neutral; in other words, be more specific. For example, instead of asking for a general major ask for specific major, i.e., history, botany, communications, etc. These specific variables could indeed give the researcher more precise information. A further possibility is to include a third type of questionnaire that deals with the respondents' self-concept and philosophical stance on life. The literature stresses the importance of these factors on attitude formation and in particular, worldminded attitudes (Allport, 1954; AFS, 1978; Kenworthy, 1952). Possibly this assessment is the pivotal factor around which worldmindedness scores cluster. 
Recommendations for Worldmindedness Development

It should be reiterated and emphasized that within the scope of the study it was not possible or intended to establish causal relationships between and among these variables in the sense of being able to say, for example, that a high level of global awareness comes about as a consequence of language interest, motivation or skill (rather than the other way around). Nonetheless, to find significant relationships among these variables Or, perhaps equally revealing, to discount such relationships was felt to constitute a very important and potentially consequential outcome in its own right.

Even though it is outside the scope of this research, implications for curriculum and recruitment in teacher education are implicit in the data. If teacher preparation is under discussion, then recruitment of intellectually more able students into the educational major is advisable. Second, attention to curriculum with inclusion of social sciences and in particular history and geography needs to be addressed.

The Task Force Statement on Education and the Worldview believes that the broadening of educational horizons must ultimately depend on the imagination and initiatives of the colleges and universities themselves (1981). It further states that the success of enlarging global dimensions depends on the expressed commitment of campus 
leadership, i.e., ample opportunity should be provided to faculty and administration to broaden their global perspectives through faculty renewal programs iñcluding institutional resources, release time, exchange programs and time abroad.

To further stimulate a global awareness in administration already ensconced in administrative positions within the existing educational system, a plan of action is recommended.

A primary knowledge base is needed on which to build. The literature indicates that (Lee, 1950; Klineberg, 1950; Allport, 1954; Mortenson, 1976) for an attitudinal change to take place, contact needs to occur and primary to that a solid foundation in a culture, its history, language and customs, is essential. Therefore, educators need to be encouraged to select an area or country of interest, and delve into its history, culture and language development. Study of the language need not be to speak (although beneficial) but to understand the development of the people's thought process.

Following an intense cognitive preparation, including daily newspaper and magazine readings that relate to the chosen country, contacts could be made with people from that country--visitors, students, visiting professors and dignitaries. It would also be advisable at that time to meet other foreign nationals to help begin to become aware 
of human commonalities.

Following this indoctrination period, a trip to the country of study would be beneficial. The critical point, if Kelman's (1970) findings are to be followed, would be to arrange meetings where satisfying status acceptance could be arranged for. Therefore, administrators meet faculty or administrators in the host country and share information.

To illustrate best this idea, an established model is taken from a program at the University of Kentucky (Harty, 1975). The model builds from introductory to developmental to intensive experiences using a hierarchy of intercultural experiences. The student is expected to move from dabbler (trying Chinese food for the first time) to student (taking a course on Chinese history and/or geography) to observer (attending a Chinese affairs film series or public meetings on trade with China) to friend (knowing a Chinese professor, student, businessperson, athlete or diplomat) to participant (travel, teacher exchange, live-in home summer experience). The program is individualized. Using this as a base and inculcating the literature findings of attitudinal requirements and status of participant, a very positive growth experience could take place.

There are a number of organizations in oregon that could help arrange contacts. The United Nations Association, World Affairs Council, Fulbright programs, Peace Corps, 
American Foreign Service (AFS), Study Abroad programs at the Institutions of Higher Education and Consulate Generals. What is needed is quality contact.

The above, of course, would only serve a positive purpose if the educator were a willing participant. Total enthusiasm would not be necessary, but some personal motivation would be.

Wallace (1977) stated that experiential education "will achieve its educational goals to the extent that it is characterized by these four objectives. That the experience is: (1) planned, (2) affective, (3) individual, and (4) thoughtfully evaluated" (p. 27). As Wilson (1982) so aptly phrased it: "A summar trip to Europe does not necessarily a global perspective make" (p. 185).

Kelman's (1962) suggestions for rewarding experiences are as follows: (1) establishment of an opportunity for a genuine involvement in an ongoing enterprise, and (2) interpersonal involvement with people in the host country (p. 77). To summarize, the overseas experience is most likely to produce favorable attitudes if it provides new information about the host country in the context of a positive interaction with some of its people.

Where do the funds for such an undertaking come from? It is not within the scope of this dissertation to offer solutions to the enumerable financial problems of such an 
endeavor, but possibilities do exist--state, federal, and private grants, sabbatical leaves, university bequests or alumni support, corporate and philanthropic donors and "seed money" to name a few.

On a less taxing financial note, informal gatherings at private homes could be arranged with guests from other lands that are here for academics, diplomacy, business or even touring. The World Affairs Council maintains a roster of foreign visitors and dignitaries (most of which do want to meet with the local inhabitants) for contact purposes.

\section{Future Research}

Further research is needed to determine what constitutes the environment in which worldmindedness is developed. Guidance may be taken from experts in attitude formation and social politicalization. Home environments such as democratic versus authoritarian style needs to be researched as well as the impact of the critical foundations of selfconcept and life philosophy. As has been pointed out in the literature, pre-experience attitude is a crucial determinant as to perception of experience received (Newman, 1977; Allport, 1954; Kenworthy, 1952; AFS, 1978).

With an improved instrument (questionnaire update, word usage and inclusion of self-concept and life attitudes) the study could then be given to a much larger sample and from different populations such as higher education faculty in social sciences and education, elementary school teachers 
and business people at large. The rationale behind this is to try to verify the position of educational level, major and course work background, foreign language study, influencing contacts, world news media acquisition, and outside travel experience as related to self-concept and worldminded attitudes. With a large sampling, a more indepth study of the eight sub-dimensions of the Worldmindedness scale could be explored. In other words, are business people more reluctant to relinquish trade and economic control to a world commission than are educators, and are educators more reluctant to release control of educational matters to a world commission than are business people, and so forth.

A longitudinal study could be conducted that included pre- and post-experience attitudes, level of intelligence (ACT/SAT/GRE/Millers), types of contacts, duration of outside experience, and status in the host country as perceived by the individual and the host country and/or family and contacts.

Much more research needs to be conducted in the area of pre- and post-testing on exchange programs for American students and teachers as well as in other areas of overseas experience (military, business, vacation). These investigations should include attitudes on worldmindedness, knowledge base, foreign language proficiency, the extent of cultural differences between the host country and native, 
position-status as viewed by host and native country and quantity and quality of contact in the host country.

This researcher believes that as the world becomes more interdependent, we will not bomb each other off the face of the earth, but suggests instead that we will work even more closely together to find solutions to existing problems. Education must play an important role in this process. Administrators in higher education in the state of Oregon, as established by this study, are generally, by their attitudes, prepared to begin the process of incorporating worldmindedness into our educational system. Even though the administrators may express a willingness to support a global awareness program, political and economic considerations of each institution and the state's budget restrictions affecting higher education have in the past and will most likely in the future prove to be an inhibiting factor in the establishment of a worldmindedness program. 


\section{BIBLIOGRAPHY}

AASCU policy statement: the international responsibility of higher education. Washington, DC: 1975. (ERIC NO. ED 121170)

AASCU policy statement: the international responsibility of higher education. Washington, DC: 1981 . (ERIC NO. ED 213352)

Abrams, Irwin. Study abroad. New dimensions in higher education, No. 6 (U.S. Department of Health, Education \& Welfare, office of Education). Washington, DC: U.S. Government Printing office, 1966.

Adorno, T. W. The authoritarian personality. New York: Harper's, 1950 .

Aikman, Louis P. \& Parker, Edmond T. Using the worldmindedness scale in cross-cultural research: an exploratory study. 1972. (ERIC No. ED 065 397)

Allport, Gordon W. The nature of prejudice. Reading, Mass.: Wesley Publishing Co., 1954.

American Field Service selection handbook. New York: AFS International/Intercultural Programs, 1978.

Anderson, Lee F. Why should American education be globalized? It's a nonsensical question. Theory into Practice, 21:3 (summer 1982), 155-161.

Angell, Robert $C$. International communication: the world society. In D. G. Scanlon (Ed.), International education: a documentary. New York: Teachers College, Columbia University, 1960.

Bakan, D. The test of significance in psychological research. Psychological Bulletin, 66 (1966) 423-437.

Baptiste, H. Multicultural teacher education: preparing educators to provide educational equity. Vol. 1 . Washington, DC: AACTE 1980. (ERIC NO. 186 355)

Barrows, T., Clark, Jr., \& Klein, S. What students know about their world. Change, May-June 1980, pp. 10-17. 
Barrows, T., Clark, Jr., \& Klein, S. College students' knowledge and beliefs: a survey of global understanding. Change, Sept. 1982. (ERIC No. ED 215 653)

Baumann, Carol Edler. International education: a look back and a look ahead. September 19\%. (ERIC No. ED 170 288)

Beauchamp, Mary. Building brotherhood. New York: Commission of Educational Organizations and National Conference of Christians and Jews, 1953.

Becker, James. Education for a global society. Bloomington, Indiana: Phi Delta Kappa Educational Foundation, 1973.

Benedict, Larry G. Traditional research versus evaluation. Unpublished report. Amherst: University of Massachusetts, 1971 .

Bjerstedt, Ake. Informational and non-informational determinants of nationality stereotypes. Journal of Social Issues, 18:1 (1962), 24-29.

Bonham, George W. Education and the world view. Change, 12: 4 (May-June 1981), 2-7.

Brademes, John. The importance of learning about the rest of the world. The Chronicle of Higher Education, $21(1982), 48$.

Bray, Charles W. III. Ascendency and decline: are we exempt. January 1981. (ERIC No. ED 191 752)

Bronfenbrenner, U. Personal communication to Otto Klineberg. In The human dimension in international relations, 1965 .

Buergenthal, Thomas, \& Torney, Judith J. International human rights and international education. June 1977. (ERIC NO. ED 134 514)

Burn, Barbara B. Strength through wisdom: the report of the President's Commission on Foreign Language and International studies. (Independent School), october 1980, 40:1, 11-17. (ERIC No. EJ 234 938)

Burn, Barbara B. Expanding the international dimension of higher education. Washington, CD: Department of Education, 1980. (ERIC No. ED 183 117) 
Burn, Barbara B. Commission report: education for an interdependent world. NASSP Bulletjn, 64:439 (November 1980). (ERIC No. EJ 234 131) (c)

Carlson, Richard 0 . Executive succession and organizational change: place-bound and career-bound superintendents of schools. Chicago: Midwest Administration Center, University of Chicago, 1962.

Carver, Ronald P. The case against statistical significance testing. Harvard Educational Review, 48:3 (August 1978), 378-399.

Charlesworth, James C., \& Lambert, Richard R. (Eds.) America's changing role as a world leader. The Annals of the AA of PSS, July 1969.

Chase, Steward. The proper study of mankind... New York: Harper \& Brothers, 1948.

Clark, C. A. Hypothesis testing in relation to statistical methodology. Review of Educational Research, 33 $(1963), 455-473$.

Cleveland, Harlan. Forward to basics: education as wide as the world. Change, 12:4 (May-June 1980), 18-22. (ERIC NO. EJ $22 \overline{8230)}$

Coello, George V. Personal growth and educational development through working and studying abroad. Journal of Social Issues, 18: I (1962), 55-67.

Cook, David R., LaFleur, N. Kenneth. A guide to educational research (2nd ed.). Boston: Allyn \& Bacon, Inc., 1975 .

Continuing the commitment. Board of foreign scholarship 8th Annual Report, October 1970.

Cornish, Edward. The study of the future. Washing:-on, DC: World Future Society, 1977.

Cronbach, I. J. Beyond the two disciplines of scientific psychology. American Psychologist, 30 (1975), 116-127.

Dillman, Don A. Mail and telephone surveys: the total design method. New York: John Wiley \& Sons, 1978 .

Edgerton, Wallace B. Who participates in education exchange? In (Ed.) Kenneth Holland, International exchange of persons: a reassessment. The Annals, 
AAPSS, March 1976, pp. 6-15.

Education for a global century: handbook lor exemplary international programs. Education and the world view, April 1982. (ERIC No. ED 210 238)

Education for international understanding and peace, with special reference to moral and civic education. 1970. (ERIC NO. ED 053 054)

Educational resources information center (ERIC) ( 9 th ed.). Phoenix, Ariz.: ORYX Press, 1982.

Evaluation of the national diffusion network. Department of Health, Education \& Welfare, Office of Education. Washington, DC: U.S. Government Printing Office, 1977.

The final act of the European Security Conference, Helsinki, Finland, August 1, 1975. Congressional Quarterly: Historic Documents of 1975. Washington, DC: Cong. Quarterly Co., 1975.

Fishbein, Martin, \& Ajzen, Iak. Belief, attitude, intention \& behavior: an introduction to theory and research. Reading, Mass.: Addison-wesley, 1975.

Flack, Michael J. Results and effects of study abroad. The Annals, AAPSS, 424, March 1976.

Frank, Lawrence $\mathrm{K}$. Society as the patient. Essays on culture and personality. New Brunswick: Rutgers Univ. Press, 1949 .

Fulton, Oliver, \& Ford, Boris. Higher education in the 80s. Universities Quarterly, 28:1, 5-58. (ERIC No. EJ 091 393)

The future of international education. Hearings before the Subcommittee on International Operations of the Committee on International Relations. House of Representatives, 95 Cong., July 1979.

Gay, L. R. Educational research. Columbus, Ohio: Charles Merrili Publishing Co., 1981.

Gilliom, M. Eugene. Global education and the social studies. Theory into practice, 20:3 (Summer 1981), 169-173. (ERIC NO. EJ 251 690)

Good, Carter V. Essentials of educational research. New York: Appleton-Century-Crofts, 1966. 
Gray, J. S., \& Thompson, A. H. The ethnic prejudices 01 white and Negro college students. Journal of Abnormal and Social Psychology, 48 (1953), 311-313.

Gress, James. Managing school/program/system. November 1979. ERIC NO. ED 188291.

Griffiths, Daniel E. Research in educational administration. New York: Columbia University Teachers College Bureau of Publications, 1959.

Hanson, E. Mark. Educational administration and organization behavior. Boston: Allyn \& Bacon, Inc., 1979.

Hanvey, Robert G. An attainable global perspective. New York: Global Perspectives Inc., 1976.

Hartley, Eugene. Problems in prejudice. New York: King's Crown Press, 1946 .

Hartshorne, Nathanial. What college students know and believe about their world. Changing (1981). (ERIC No. ED 218 319)

Harty, Harold. Pre-service teachers' eye view of prestudent teaching community based experience in poor minority settings. U.S. Department of Health, Education \& Welfare. Washington, DC: U.S. Government Printing Office, 1975.

Harvard's report on the core curriculum. Chronicle of Higher Education, March 6, 1978.

Hays, W. L. Statistics. New York: Holt, Rinehart \& Winston, 1963.

Heenan, David A., \& Perlmutter, Howard V. Multinational organization development. Reading, Mass.: Addison Wesley, 1979 .

Hefferlin, J. L. Dynamics of academic reform. San Francisco: Jossey-Bass, 1969.

Hensley, Thomas B. et al. Teaching political science in a study abroad program: an examination of impacts on student attitudes. Kent State University: 1979. (ERIC NO. ED 159 101)

Hensley, Thomas R., \& Sell, Deborah K. A study abroad program: an examination of impacts on student attitudes. Teaching political science, $\underline{6}: 4$ (July 1979). (ERIC NO. EJ 205507) 
Holland, Kenneth (Ed.). International exchange of persons: a reassessment. Philadelphia: The Annals AAPSS.

Hull, W. Frank. The American undergraduate off-campus and overseas: interim report. Toledo, Ohio: Center for Study of Higher Education, Toledo University, 1974.

Iisager, Holger. An evaluation of an attempt to form international attitudes. The Journal of Social Psychology, $30(1949), 207-216$.

International educational and cultural exchange. The Bureau of Educational and Cultural Affairs: U.S. Department of State, March 1974.

Jacobson, Eugene $\mathrm{H}$. Sojourn research: a definition of the field. The Journal of Social Issues, 19:3 (July 1963), 123-129.

Johnson, Lyndon Baines. Speech at the bicentennial celebration of the birth of the founder of the smithsonian Institution, September 16, 1956, quoted by Wells, Herman $B^{\prime}$, The responsibility of the intellect. In (Ed.) Allan A. Michie, Diversity and interdependence through international education: Washington, DC: The Board of Foreign Scholarships, 1966 .

Kelman, Herbert $C$. Changing attitudes through international activities. Journal of Social Issues, $18(1962), 65-87$.

Kelman, Herbert C., \& Ezekiel, Raphael S. Cross-national encounters. San Francisco: Jossey-Bass, Inc., 1970.

Kenworthy, Leonard s. World horizons for teachers. New York: Columbia College Press, 1952.

Kenworthy, Leonard s. The interactional dimension of education. Washington, DC: Association for Supervision and Curriculum Development, 1970.

Kerr, Clark. Education for global perspectives. The Annals, AAPSS, 442, March 1979.

Keynote address and background papers. National Assembly on Foreign Language and International studies, Racine, Wisconsin, October 30-November 1, 1980. (ERIC No. ED 213270 )

King, David C. Education for a world change: a report. New York: Global Perspectives Inc., 1980. 
King, Edith w. Worldmindedness: the world: context for teaching in the elementary school. Washington, DC: Office of Education, Bureau of Educational Personnel Development, October 1971. (ERIC No. ED 052 094)

King, Maxwell. Advancing international education. San Francisco: Jossey-Bass, 1979.'(a)

King, Maxwell, \& Brender, Robert I. (Eds.). New directions for community colleges: advancing international education. San Francisco: Jossey-Bass, Inc., 1979.

Klassen, Frank H., \& Leavitt, Howard B. Teacher education and global perspectives. Washington, DC: National Institution of Education, 1982.

Kleska, William R., Nie, Norman H., \& Hull, C. Hadlai. SPSS Primer. New York: MCGraw-Hill Book Co., 1975.

Klineberg, otto. The human dimension in international relations. New York: Holt, Rinehart \& Winston, 1965.

Klineberg, Otto. Social Psychology. New York: Henry Holt \& Co., 1954.

Klineberg, otto. Tension affecting international understanding: a survey of research. New York: Social Science Research Council, 1950.

Krech, David, \& Crutchfield, Richard. Theory and problems of social psychology. New York: McGraw-Hill, 1948.

Laban, Patricia J. Advanced Questionnaire Design. Cambbridge, Mass.: Abt Books, 1980.

Lambert, R. D. Indian students on an American campus. Minneapolis: University of Minnesota Press, 1956.

Tambert, R. D. (Ed.). New directions in international education. The Annals of the AAPSS. May 1980.

Lawson, Terrence (Ed.). Education for international understanding. Hamburg, Germany: UNESCO Institute for Education, 1969.

Lee, Irving J. How do you talk about people? Anti-Defamation League of $\mathrm{B}^{\prime}$ nai $\bar{B}^{\prime}$ rith, 1950.

Lehrer, Stanley (Ed.). Leaders, teachers, \& learners in academe: partners in the educational process. New York: Appleton-Century-Crofts, 1970. 
Lemon, N. Attitudes and Their Measurement. New York: John Wiley, 1973.

Lentz, T. F. The psychology of international-mindedness studied by the method of opinion correlates. psychological Bulletin, 33 (1946), 732 .

Lentz, T. F. The attitudes of world citizenship. Journal of Social Psychology, 23 (1950), 207-214.

Levine, Arthur, \& Weingart, John. Reform of undergraduate education. San Francisco: Jossey-Bass, 1974 .

Lewin, Kurt. Resolving social conflicts. New York: Harper \& Brothers, 1945.

Magrath, Peter C. International education and language studies: a question and a proposal. Change, May-June 1982, pp. 8-9.

Marker, Gerald. Global education: an urgent claim on the social studies curriculum. Social Education, 41 , 1977.

Martorana, S. V., \& Kuhns, Eileen. Managing academic change. Interactive forces and leadership in higher education. San Francisco: Jossey-Bass, 1975.

Martorana, S. V., \& Shannon, W. G. International education, the college, and the community: a framework for action. In Maxwell King (Ed.), Advancing international education, pp. 11-19. San Francisco: JosseyBass, 1979.

McCall, Chester H. Jr. Sampling and statistics handbook for Research in education. Washington, DC: National Education Association, 1980.

Mische, Gerald, \& Mische, Patricia. Toward a human world order. New York: Paulist Press, 1977.

Morrison, D. E., \& Henkel, R. E. The significance test controversy--a reader. Chicago: Aldine, 1970.

Morse, Nancy, \& Allport, F. The causation of anti-semitism: an investigation of hypotheses. Journal of Psychology, 34, (1952), 197-233.

Mort, Paul R. Educational adaptability. In Administration for adaptability. New York: Metropolitan School study Council, 1958, pp. 32-33. 
Mort, Paul R., \& Ross, Donald. Principles of school administration. New York: McGraw-Hill, 1957.

Mortenson, Paul. Attitudes of prospective teachers toward the culturally different. Education, 115 (1976), 614.

Naisbit, John. Megatrends: ten new directors transforming our lives. New York: Warner Books, 1982.

Nason, John $W$. The college and world affairs. Report of the Committee of the College and World Affairs, 1964.

Newman, Arthur. National identity and worldmindedness. Social Studies, 68(4) (July-August 1977).

Nunnally, J. C. The place of statistics in psychology. Educational and Psychological Measurement, 20 (1960), 641-650.

Orlich, Donald C. Designing sensible surveys. Pleasantville, N.Y., I978.

Owens, Robert G. Organizational behavior in education. Englewood Cliffs, N.J.: Prentice-Hall, 1981.

Pellicano, Roy P. Global education: a macro perspective for citizenship education. Social Studies, 73:3 (May-June 1981), 125-129.

Perkins, James, \& Burn, Barbara. International education in a troubled world. Annals AAPSS, 449 (May 1980), 17-30.

Persistence and regression of changed attitudes: language range studies. Journal of Social Issues, 19:4 $(1963), 3-14$.

Phillips, June $\mathrm{K}$. Introduction: language is the link. ACTFL Foreign Language Education Series, 9 (1977), $1-6$. (a)

Phillips, June $k$. The language connection: from the classroom to the world. ACTFL Foreign Language Education Series, 9 (1977), 21-28. (b)

Pike, Lewis. Other nations, other people: a survey of student interests, knowledge, attitudes and perceptions. U.S. Department of Health, Education \& Welfare, Office of Education. Washington, DC: U.S. Government Printing Office, 1979. 
Posvar, Wesley $w$. Toward an academic response. Change, $\underline{12}(1980)$.

Queener, Lleywellyn. The development of international attitudes. Journal of Social Psychology, 29 (1949): I. Hypotheses and verification, 221-235; II. Attitudes cues and prestige, 237-252; III. The literature and a point of view, 30, 105-126.

Reinhardt, John E. Remarks by John E. Reinhardt, Director, International Communication Agency, 1980.

Remy, Richard, et al. International learning and international education in a global age. Bulletin 47. National Council for the Social studies, 1975.

Rhinesmith, Stephen. Americans in the global learning process. Annals of AAPSS, 442 (March 1979), 91-108.

Richardson, John J. (Ed.). The human dimension of foreign policy: an American perspective. The Annals of the AAPSS (March 1979), 15-20.

The role of the scholarly disciplines. New Rochelle, N.Y.: Council on Learning, Charge Magazine Press, 1980.

Rosell, Leif. Children's views of work and love. Journal of Primary Research, $\underline{5}$ (1968), 268-276.

Roskens, Ronald $W$. Legacies of the Tower of Babel. Modern Language Journal, 64(2), 1980, 173-178.

Rozeboom, W. W. The fallacy of the null hypothesis significance test. Psychological Bulletin, 57 (1960), 416-428.

Sampson, Donald, \& Smith, Howard P. A scale to measure world-mindedness attitudes. The Journal of Social Psychology, 45 (1957), 99-106.

Scanlon, David G. (Ed.). International education: a documentary history. New York: Teachers College, Columbia University, 1960.

Schiel, Erling 0 . The foreign student as stranger, learning the norms of the host culture. Journal of Social Issues, 18:1 (1962), 41-53.

Sellitz, C., \& Cook, S. W. Factors influencing attitudes of foreign students toward the host country. Journal of Social Issues, 18:1 (1962), 7-23. 
Shaw, Marvin E., \& Wright, Jack M. Scales for the measurement of attitudes. New York: McGraw-Hill, 1967.

Simmons, Dale D. Humanistic worldmindedness and peace proposal preferences in Pacifist, ROTC, and random student samples, 1971 .

Simon, Paul. The United States crisis in foreign language. Annals of AAPSS, 449 (May 1980), 31-44.

Smith, Howard P. Do intercultural experiences affect attitudes? Journal of Abnormal and Social Psychology, 41 (1955), 469-477.

Spaulding, Seth, \& Flack, M. J. The world's students in the United States. U.S. Department of State, Office of External Research. Washington, DC: U.S. Government Printing office, 1975.

Speakman, Cummins E. Jr. International exchange in education. New York: The Center for Applied Research in Education, Inc., 1966.

Stagner, R. A note on education and international attitudes. Journal of Social Psychology, 16 (1942), $341-345$.

Strasheim, Lorraine A. An issue on the horizon: the role of foreign languages in global education. Foreign Language Annals, 12:1 (1979), 29-33.

Sweeney, JoAnn, \& Zandan, Peter A. Comparing ourselves to others: international knowledge and attitudes. Social Studies, 73:3 (May-June 1982), 135-142.

Targ, Harry. Children's orientations to international politics. Journal of Peace Research, 7 (1970), 79-98.

Task Force statement on education and the world view. November 1981. (ERIC No. ED 203 826)

Taylor, H. The world and the American teacher. The preparation of teachers in the field of world affairs. AAC for Teacher Education, 1968.

Teeche, David J. The diffusion of an administrative innovation. Management Science, 26:5 (May 1980), $464-470$.

Thompson, Richard T. New directions in foreign language study. In Richard T. Thompson (Ed.), New directions in international education. Annals of AAPSS, May 1980. 
Tonkin, Humphrey, \& Edwards, Jane. The world in the curriculum. New York: Change Magazine Press, 1981.

Torney-Purta, Judith $V$. The role of NIE in stimulating research on international education: learning issues, testing, and assessment. Washington, DC: National Council on Education Research, 1981.

Torney-Purta, Judith V. The global awareness survey: implications of teacher education. Theory into Practice, 21:3 (Summer 1982), 200-205.

Toward education with a global perspective: a report of the National Assembly on Foreign Language and International Studies, Racine, Wisconsin, October 30,1980 .

Toynbee, Arnold. Civilization on Trial. New York: Oxford University Press, 1947.

Urso, Ida. Teacher's resource manual on worldmindedness: an annotated bibliography of curriculum materials, kindergarten through grade twelve. Occasional Paper No. 8. Los Angeles, CA: University of California Press, 1981.

Vance, Cyrus R. Education and the world view, IV.

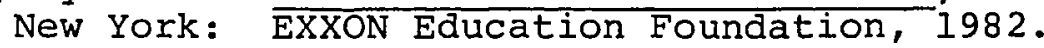

Wallace, John A. The educational values of experiential education. In D. Batchelder and E. Warner (Eds.), Beyond Experience. Brattleboro, VT: The Experiment Press, 1977.

Williams, R. M. The reduction of intergroup tensions. Social Science Research Council Bulletin, 57 (1947), 71 .

Willner, Robert T. Oregon Governor's Commission on Foreign Language and International Studies Report. June, 1982.

Wilson, Argene H. Cross-cultural experiential learning for teachers. Theory into Practice, 21:3 (Summer 1982), 184-192.

Zimmerman, Alfred. Project for a UNESCO educational centre. London: Privately Printed, 1946. 
APPENDIX A

TABLES I THROUGH XIII 
TABLE I

DEMOGRAPHIC VARIABLES OF THE RESPONDENTS

SEX, AGE, ETHNICITY AND SEX

\begin{tabular}{|c|c|c|}
\hline $\begin{array}{l}\text { Demographic } \\
\text { Variables }\end{array}$ & $\mathrm{n}$ & $\frac{\gamma}{6}$ \\
\hline \multirow[t]{2}{*}{$\begin{array}{l}\text { Sex } \\
\text { Male } \\
\text { Female }\end{array}$} & $\begin{array}{r}53 \\
7 \\
\end{array}$ & $\begin{array}{l}88.3 \\
11.7 \\
\end{array}$ \\
\hline & 60 & 100.0 \\
\hline \multirow[t]{2}{*}{$\begin{array}{l}\text { Age } \\
39 \text { or under } \\
49 \text { or under } \\
59 \text { or under } \\
65 \text { or under }\end{array}$} & $\begin{array}{r}4 \\
26 \\
21 \\
9 \\
\end{array}$ & $\begin{array}{r}6.7 \\
43.3 \\
35.0 \\
15.0 \\
\end{array}$ \\
\hline & 60 & 100.0 \\
\hline $\begin{array}{l}\text { Ethnic Backgro } \\
\text { Black } \\
\text { Chicano } \\
\text { Asian } \\
\text { Caucasian }\end{array}$ & $\begin{array}{r}2 \\
1 \\
2 \\
55 \\
60\end{array}$ & $\begin{array}{r}3.3 \\
1.7 \\
3.3 \\
91.7 \\
100.0\end{array}$ \\
\hline $\begin{array}{l}\text { Sex of Ethnic } \\
\text { Male } \\
\text { Female }\end{array}$ & $\begin{array}{l}4 \\
1 \\
\end{array}$ & $\begin{array}{l}80.0 \\
20.0 \\
\end{array}$ \\
\hline & 5 & 100.0 \\
\hline
\end{tabular}


TABLE II

ADMINISTRATORS IN HIGHER EDUCATION

IN THE UNITED STATES (ALL STATES)

SEX AND ETHNICITY

Demographic

Variable

Sex

Male

Female

Ethnic Background

Caucasian

Minority

Minority Male

Minority Female
71.9

28.1

86.0

14.0

12.2

1. 8 
TABLE IIII

RESPONDENTS' PARENTS' EDUCATIONAL LEVEL

\begin{tabular}{|c|c|c|c|}
\hline $\begin{array}{l}\text { Education } \\
\text { Variable }\end{array}$ & & Mother & Father \\
\hline $\begin{array}{l}\text { Less than } \\
\text { High school }\end{array}$ & $\begin{array}{l}\mathrm{n} \\
\mathrm{q}\end{array}$ & $\begin{array}{l}14 \\
23.3\end{array}$ & $\begin{array}{l}20 \\
33.3\end{array}$ \\
\hline $\begin{array}{c}\text { High School } \\
\text { Diploma }\end{array}$ & $\begin{array}{l}n \\
8\end{array}$ & $\begin{array}{l}23 \\
38.3\end{array}$ & $\begin{array}{l}16 \\
26.7\end{array}$ \\
\hline Some College & $\begin{array}{l}\mathrm{n} \\
z\end{array}$ & $\begin{array}{l}16 \\
26.7\end{array}$ & $\begin{array}{l}13 \\
21.7\end{array}$ \\
\hline Bach degree & $\begin{array}{l}\mathrm{n} \\
\mathrm{q}\end{array}$ & $\begin{array}{l}4 \\
6.7\end{array}$ & $\begin{array}{l}5 \\
8.4\end{array}$ \\
\hline \multirow[t]{2}{*}{ Graduate Degree } & $\begin{array}{l}n \\
8\end{array}$ & $\begin{array}{l}2 \\
3.3 \\
\end{array}$ & $\begin{array}{l}5 \\
8.3 \\
\end{array}$ \\
\hline & $\begin{array}{l}\text { Missing } \\
\text { TOTAL }\end{array}$ & $\begin{array}{l}1 \\
60.0 \\
100.08\end{array}$ & $\begin{array}{c}1 \\
60.0 \\
100.0 \%\end{array}$ \\
\hline
\end{tabular}


TABLE IV

RESPONDENTS TRAVEL OUTSIDE THE UNITED STATES

\begin{tabular}{lcc}
\hline $\begin{array}{l}\text { Travel } \\
\text { Variable }\end{array}$ & $\mathrm{n}$ & 8 \\
\hline Vacation & 47 & 78.3 \\
Business & 26 & 43.3 \\
Military & 23 & 28.3 \\
Teaching & 10 & 16.7 \\
Other & 10 & 16.7 \\
Student & 6 & 10.0 \\
\hline
\end{tabular}


TABLE V

RESPONDENTS' MAJOR FIELD OF STUDY

FOR BACHELOR'S, MASTER'S, AND DOCTORATES

\begin{tabular}{lrr}
\hline Degree Variable & $\mathrm{n}$ & \multicolumn{1}{c}{} \\
\hline Bachelor's & & \\
Science & 12 & 20.0 \\
Social Sciences & 20 & 33.3 \\
Business & 3 & 5.0 \\
Education & 8 & 13.3 \\
Arts \& Letters & 8 & 13.3 \\
Other & 1 & 1.7 \\
Combination* & 3 & 5.0 \\
& & \\
Master's & & \\
Science & & 8.3 \\
Social Sciences & 5 & 31.7 \\
Business & 19 & 6.7 \\
Education & 4 & 28.3 \\
Arts \& Letters & 17 & 8.3 \\
Other & 5 & 1.7 \\
Combination* & 1 & 6.7 \\
Doctorate & 4 & \\
Science & & \\
Social Science & & \\
Business & & \\
Education & 4 & 6.7 \\
Arts \& Letters & 17 & 28.3 \\
Other & 2 & 3.3 \\
Combination* & 17 & 28.3 \\
& 4 & 6.7 \\
\hline
\end{tabular}

Combinations:

Bachelor's. 1. Science and Arts \& Letters

Master's $\quad$ 2. Social Science and

2. Science and Education

3. Education and Arts

4. Social sciences and education

Doctorate 1. Science and Others

2. Social services and education 
TABLE VI

RESPONDENTS' COURSEWORK CONTRIBUTING

TO WORLD AWARENESS

\begin{tabular}{lcc}
\hline Coursework Variable & $\mathrm{n}$ & $\frac{8}{8}$ \\
\hline Social Science & 56 & 93.3 \\
Literature, English, Journalism & 31 & 51.7 \\
Economics and Business & 26 & 43.3 \\
Philosophy and Religion & 26 & 43.3 \\
Modern Languages & 25 & 41.7 \\
Education & 16 & 26.7 \\
Ancient Languages & 14 & 23.3 \\
Sciences & 11 & 18.3 \\
Environmental Studies & 6 & 10.0 \\
Other & 2 & 3.3 \\
\end{tabular}

Note: multiple answers 
TABLE VII

RESPONDENTS' WORLDMINDEDNESS SCALE SCORES

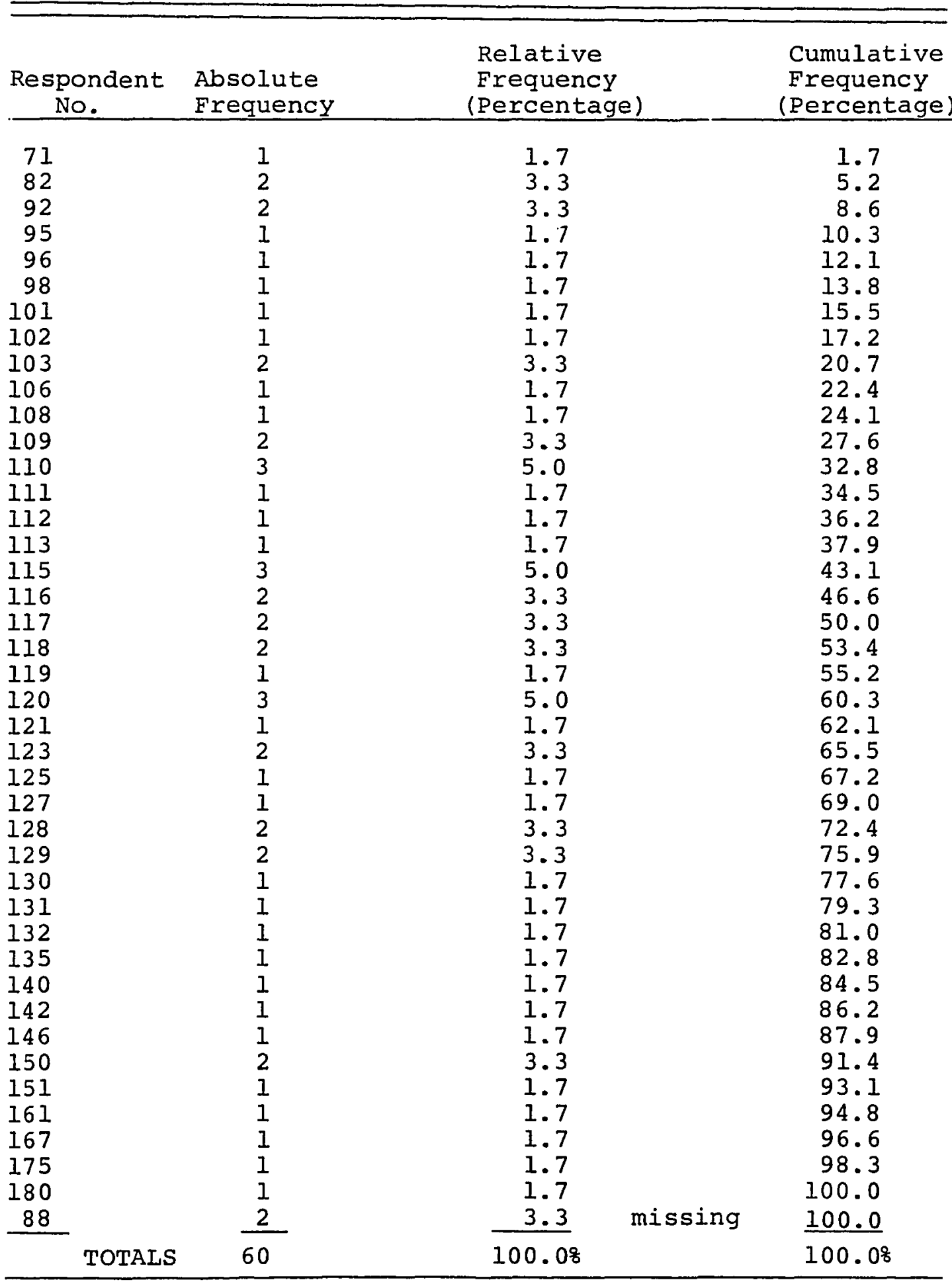

Standard Deviation $=21.69 \quad$ Median $=117.01$ 
TABLE VIII FOREIGN IAANGUAGE STUDY

\begin{tabular}{|c|c|c|c|c|}
\hline Major & $\frac{\text { None }}{0}$ & $\frac{1 \text { to } 2 \text { yrs. }}{1}$ & $\frac{\text { More than }}{2}$ & TOTAL \\
\hline Missing & & & $\begin{array}{l}1 \\
1.7\end{array}$ & $\begin{array}{l}1 \\
1.7\end{array}$ \\
\hline Sciences & $\begin{array}{l}1 \\
1.7\end{array}$ & $\begin{array}{l}4 \\
6.7\end{array}$ & $\begin{array}{l}2 \\
3.3\end{array}$ & $\begin{array}{l}7 \\
11.7\end{array}$ \\
\hline Social Science & $\begin{array}{l}0 \\
0\end{array}$ & $\begin{array}{r}6 \\
10\end{array}$ & $\begin{array}{l}12 \\
20\end{array}$ & $\begin{array}{l}18 \\
30.0\end{array}$ \\
\hline Business & $\begin{array}{l}0 \\
0\end{array}$ & $\begin{array}{l}1 \\
1.7\end{array}$ & $\begin{array}{l}2 \\
3.3\end{array}$ & $\begin{array}{l}3 \\
5.0\end{array}$ \\
\hline Education & $\begin{array}{l}4 \\
6.7\end{array}$ & $\begin{array}{r}9 \\
15\end{array}$ & $\begin{array}{c}6 \\
10\end{array}$ & $\begin{array}{l}19 \\
1.7\end{array}$ \\
\hline Arts \& Letters & $\begin{array}{l}0 \\
0\end{array}$ & $\begin{array}{l}3 \\
5 .\end{array}$ & $\begin{array}{l}2 \\
3.3\end{array}$ & $\begin{array}{l}5 \\
8.3\end{array}$ \\
\hline Other & $\begin{array}{l}0 \\
0\end{array}$ & $\begin{array}{l}1 \\
1.7\end{array}$ & $\begin{array}{l}1 \\
1.7\end{array}$ & $\begin{array}{l}2 \\
3.3\end{array}$ \\
\hline Comisination & $\begin{array}{l}1 \\
1.7\end{array}$ & $\begin{array}{l}0 \\
0\end{array}$ & $\begin{array}{l}4 \\
6.7\end{array}$ & $\begin{array}{l}5 \\
8.3\end{array}$ \\
\hline 8 TOTAL & $10.0 \%$ & 40.08 & 50.08 & 100.08 \\
\hline $\mathrm{N}$ TOTAL & 6 & 24 & 30 & 60 \\
\hline
\end{tabular}


TABLE IX

RESPONDENTS' WORLDMINDEDNESS SCORE AND OUTSIDE EXPERIENCE DURATION

Worldminded

Score

$$
0
$$

1

Total

$\begin{array}{llll} & & & \\ & & & \\ & n & 0 & \\ 8 & 0.9 & & \end{array}$

n $n$

$8 \quad 0$

$0 \quad 8$

\& 0.9

13.8

0.90

13.8

M $\quad 2$

83.4

36

62.1

3

5.2

41

$\mathrm{H}$

$\begin{array}{ll}\mathrm{n} & 1 \\ 8 & 1.7\end{array}$

8

13.8

0

0

15.5

Total

$\begin{array}{ll}\mathrm{n} & 3 \\ \mathrm{q} & 5.2\end{array}$

52

89.7

5. 2

58

100 
TABLE X

RESPONDENTS' TOTAL MAJORS

FOR HIGH SCORES

Major

$\begin{array}{llllllllll}\text { Frequency } & 1 & 2 & 3 & 4 & 5 & 6 & 7 & 8 & 9\end{array}$

Variable

Arts \& Letters

Social Sciences

Sciences

Education

FOR LOW SCORES

Major

\begin{tabular}{llllllllll} 
Frequency & 1 & 2 & 3 & 4 & 5 & 6 & 7 & 8 & 9 \\
\hline
\end{tabular}

Variable

Business

other

Education

Sciences

Social Sciences 
TABLE XI

RESPONDENTS' INSTITUTION, WORLDMINDEDNESS SCALE AND POLITICAL PARTY AFFILIATION

Institution

Worldminded Score

Democrat Republican

Other

Total

$\begin{array}{lllll}\text { n } & \text { q } & \text { n } & \text { q } & \text { n }\end{array}$

Community college

\begin{tabular}{|c|c|c|c|c|c|c|c|}
\hline L & 2 & 10.0 & 1 & 5.0 & 0 & 0 & 3 \\
\hline & 12 & 60.0 & 4 & 20.0 & 1 & 5.0 & 17 \\
\hline & 0 & 0 & 0 & 0 & 0 & 0 & 20 \\
\hline & 14 & 70.0 & 5 & 25.0 & 1 & 5.0 & $100 \%$ \\
\hline
\end{tabular}

Private colleges

\begin{tabular}{|c|c|c|c|c|c|c|c|}
\hline L & 0 & 0 . & 1 & 6.3 & 0 & 0 & 1 \\
\hline M & 9 & 56.3 & 2 & 12.5 & 0 & 0 & 11 \\
\hline $\mathrm{H}$ & 4 & 25.0 & 0 & 0 & 0 & 0 & \\
\hline & 13 & 81.3 & 3 & 18.8 & 0 & 0 & 1009 \\
\hline
\end{tabular}

4-Year Colleges

\begin{tabular}{|c|c|c|c|c|c|c|c|}
\hline I & 1 & 5.0 & 2 & 10.0 & 1 & 5. & 4 \\
\hline M & 6 & 30.0 & 3 & 15.0 & 3 & 15 & 12 \\
\hline $\mathrm{H}$ & 1 & 5.0 & 1 & 5.0 & 2 & 10. & 4 \\
\hline & 8 & 40.0 & 6 & 30.0 & 6 & 30.0 & $100 \%$ \\
\hline
\end{tabular}


TABLE XII

RESPONDENTS' INSTITUTION OF EMPLOYMENT

AND HIGHEST DEGREE EARNED

\begin{tabular}{lccccc}
\hline \hline $\begin{array}{l}\text { Institution } \\
\text { Variable }\end{array}$ & & Bachelor & Master & Doctorate & Total \\
\hline $\begin{array}{l}\text { Community } \\
\text { College }\end{array}$ & $\mathrm{n}$ & 0 & 7 & 13 & 20 \\
& o & 0 & 35.0 & 65.0 & $100.0 \%$ \\
$\begin{array}{l}\text { Private } \\
\text { Colleges }\end{array}$ & $\mathrm{n}$ & 1 & 1 & & \\
& 8 & 5.9 & 5.9 & 88.2 & 17 \\
State & $\mathrm{n}$ & 0 & 3 & & 100.08 \\
Schools & 8 & 0 & 15.0 & 85.0 & 100.08 \\
& & & & & \\
\hline
\end{tabular}


TABLE XIII

RESPONDENTS' INSTITUTION OF EMPLOYMENT AND

LENGTH OF FOREIGN LANGUAGE STUDY

\begin{tabular}{|c|c|c|c|c|c|}
\hline & & Never & $\begin{array}{c}\text { no more } \\
\text { than } 2 \text { yrs. }\end{array}$ & $\begin{array}{c}\text { more than } \\
2 \text { years }\end{array}$ & TOTAL \\
\hline $\begin{array}{l}\text { Community } \\
\text { College }\end{array}$ & $\begin{array}{l}n \\
\frac{8}{6}\end{array}$ & $\begin{array}{r}6 \\
30\end{array}$ & $\begin{array}{l}7 \\
35.0\end{array}$ & $\begin{array}{c}7 \\
35.0\end{array}$ & $\begin{array}{l}20 \\
100.08\end{array}$ \\
\hline $\begin{array}{l}\text { Private } \\
\text { Colleges }\end{array}$ & $\begin{array}{l}n \\
\frac{8}{8}\end{array}$ & $\begin{array}{l}0 \\
0\end{array}$ & $\begin{array}{c}8 \\
47.1\end{array}$ & $\begin{array}{l}9 \\
52.9\end{array}$ & $\begin{array}{l}17 \\
100.08\end{array}$ \\
\hline $\begin{array}{l}\text { State } \\
\text { Schools }\end{array}$ & $\begin{array}{l}\mathrm{n} \\
\frac{q}{8}\end{array}$ & $\begin{array}{l}0 \\
0\end{array}$ & $\begin{array}{l}9 \\
45.0\end{array}$ & $\begin{array}{l}11 \\
55.0\end{array}$ & $\begin{array}{l}20 \\
100.08\end{array}$ \\
\hline
\end{tabular}


APPENDIX B

COVER LETTER AND FOLLOW-UP CORRESPONDENCE 
February ]4, 1983

\section{Dear Educator:}

Over the last three years, the Council of Learning and a national task force of educators have examined the capacity of the country's colleges and universities to provide college students with an adequate understanding of the world. The Task Force Statement on Education and the World View states, "The strength and success of enlarging global dimensions of the college experience will depend on the expressed commitment of the campus leadership."

In keeping with the federal government's study, the Oregon Governor's Commission on Foreign Language and International Studies was established in July 1980. The findings of this commission recommended that "All educational institutions, especially at the postsecondary level, emphasize international issues in conducting community education programs, stressing the local and regional impact of those issues."

To help educators meet the recommendations of the President's task force and the Governor's Commission, we have developed a study to help assess the awareness and stance of administrators in higher education in the state of oregon. The outcome of this research wi11 be made available to the executive director of the Governor's Commission, Robert T. Wilner.

Your contribution (anonymous) will enhance the State's ability to determine the point from which the planning and implementation of the recommendations may begin.

Please take the next ten minutes to fill out and return the enclosed questionnaire by February 22, 1983, in the pre-stamped envelope.

Your cooperation is greatly appreciated.

Yours truly,

Elizabeth 0'Malley

Research Assistant

EO: dc 


\section{FIRST POST CARD}

$2 / 25 / 83$

Dear Educator,

On February 14, 1983 a questionnaire was sent to you concerning global awareness. Because it was sent to only a small, representative sample, it is extremely important that yours be returned. Thank you for your assistance.

Sincerely,

Elizabeth O'Malley Research Assistant 
March 14, 1983

About four weeks ago I wrote to you seeking help in assessing the awareness and stance of administrators in higher education in the state of Oregon regarding enlarging global dimensions of the college experience. As of today we have not received your completed questionnaire.

Our research has been undertaken to help educators meet the recommendations of the President's task force on Education and the World View and the Governor's Commission on Foreign Language and International Studies.

I am writing to you again because of the significance each questionnaire has to the usefulness of this study. Your contribution will enhance the State's ability to determine the point from which the planning and implementation of the recommendations may begin.

You may be assured of complete confidentiality. The questionnaire has an identification number for mailing purposes only. This is so that we may check your name off the mailing list when your questionnaire is returned. In the event that your questionnaire has been misplaced, a replacement is enclosed.

Your contribution to the success of this study will be appreciated greatly.

Cordially,

Elizabeth O'Malley

Research Assistant

E0: dc 
SECOND POST CARD

\section{$4 / 4 / 83$}

Dear Educator:

We have not yet received your completed questionnaire of the first statewide study dealing with global awareness in conjunction with state and federal directives on this issue. Therefore, the results are of particular importance and I urge you to return the questionnaire as soon as possible.

Thank you,

Elizabeth O'Malley Research Assistant 
APPENDIX C

QUESTIONNAIRE 
PLEASE NOTE:

Copyrighted materials in this document have not been filmed at the request of the author. They are available for consultation, however, in the author's university library.

These consist of pages:

P. 155-161

\section{University}

Microfilms

International

300 N. ZEEB RD.. ANN ARBOR, MI 48106 (313) 761.4700 